\title{
JOSÉ ÁNGEL SESMA MUÑOZ. TRAYECTORIA ACADÉMICA E ITINERARIOS HISTORIOGRÁFICOS
}

\author{
JOSÉ ÁNGEL SESMA MUÑOZ. HIS CAREER AND HISTORICAL WORK
}

\author{
Mario Lafuente Gómez \\ Universidad de Zaragoza
}

\begin{abstract}
Resumen: Este artículo ofrece una reflexión historiográfica sobre la obra del historiador José Ángel Sesma Muñoz (Zaragoza, 1946), catedrático de Historia Medieval en la Universidad de Zaragoza y académico numerario de la Real Academia de la Historia. En su primera parte, se analiza su trayectoria académica, desde sus comienzos como doctorando hasta el presente. A continuación, en la segunda parte, se examinan las aportaciones más relevantes de su producción historiográfica en torno a tres ejes principales: la política, la economía y la sociedad.
\end{abstract}

Palabras clave: Historiografía, Historia Medieval, Historia de Aragón, Política, Economía, Sociedad.

\begin{abstract}
The purpose of this article is to analyze the historiographic career of José Ángel Sesma Muñoz (Saragossa, 1946), professor of Medieval History in the University of Saragossa and member of the Spanish Royal Academy of History. The article is organized in two different parts. The first one is focused on the academic aspects, from his beginnings as a $\mathrm{PhD}$. student till the present. In the second part, we examine the keys of his historical work through three main subjects: politics, economy and society.
\end{abstract}

Keywords: Historiography, Medieval History, History of Aragon, Politics, Economy, Society. 


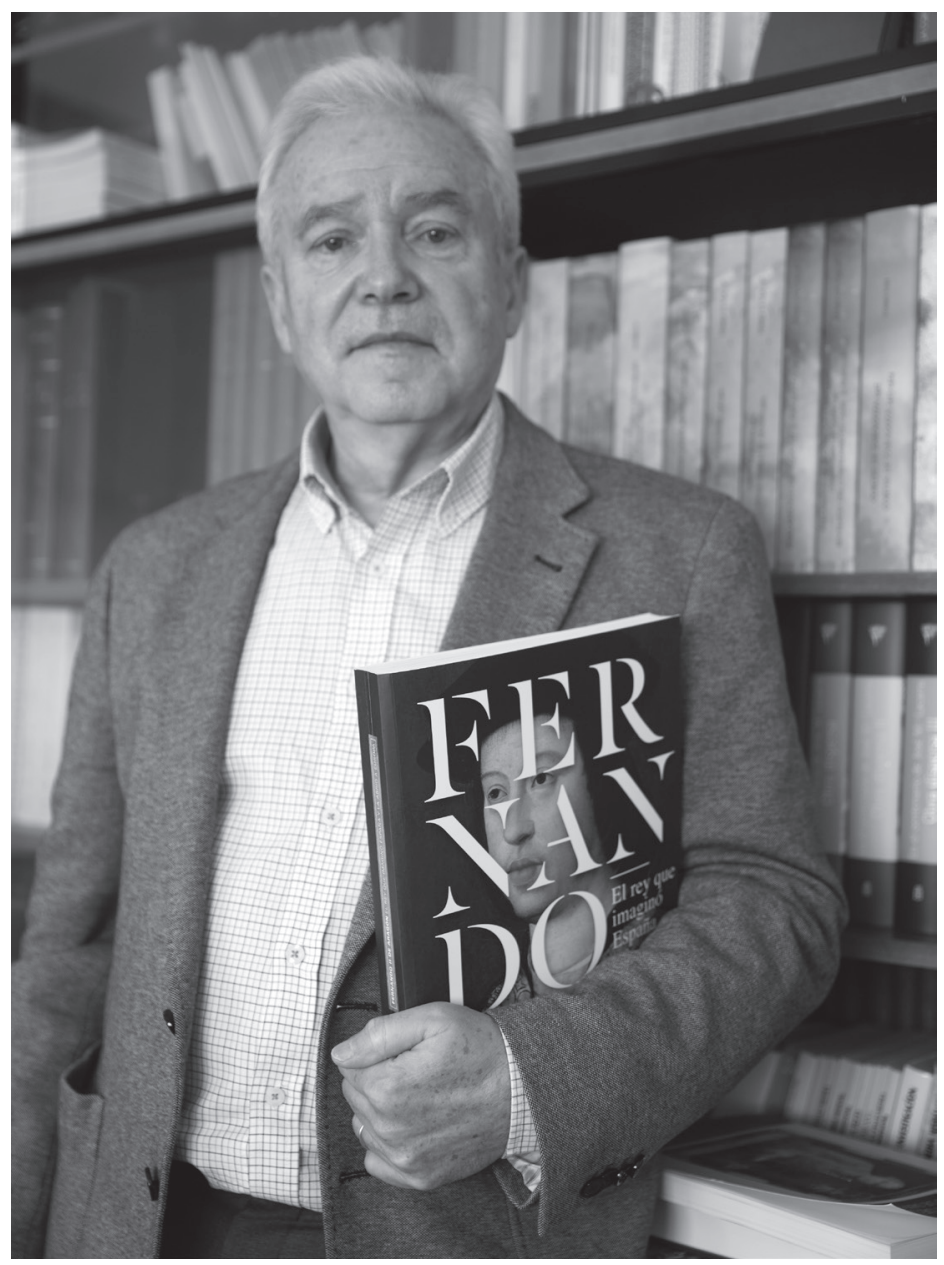

Ángel Sesma en su despacho de la Facultad de Filosofía y Letras de Zaragoza.

Fotografía: Javier Cebollada 


\section{Introducción*}

Cualquier reflexión historiográfica que aspire, si no a la objetividad, sí, al menos, a la veracidad y honestidad profesionales exige, inevitablemente, de un ejercicio de distanciamiento previo, tanto más difícil de realizar cuanto más próximo se encuentra el contexto estudiado del propio entorno, académico y vital, de quien se dispone a llevarla a cabo. La dificultad se incrementa cuando, como en este caso, se trata de elaborar una síntesis acerca del recorrido académico e historiográfico de alguien en cuya compañía se ha aprendido no sólo a interpretar y explicar la Historia, sino, sobre todo, a entender y practicar el oficio de historiador. José Ángel Sesma, catedrático de Historia Medieval de la Universidad de Zaragoza desde hace veinticinco años y miembro numerario de la Real Academia de la Historia, es una de las figuras clave del medievalismo español de las últimas cuatro décadas, en las que ha contribuido decisivamente a situar la Historia de Aragón en la Baja Edad Media dentro de las tendencias historiográficas más recientes del medievalismo europeo, tanto a través de sus propios trabajos de investigación como, simultáneamente, mediante el estímulo y dirección de tesis doctorales y proyectos colectivos.

Esas cuatro décadas representan, exactamente, el tiempo transcurrido entre dos hitos especialmente significativos en la carrera del profesor Sesma, en concreto la defensa de su tesis doctoral, realizada el 20 de noviembre de 1976, y su jubilación del profesorado, prevista para el final del actual curso académico (2015-2016). La relevancia de estos dos momentos justifica que sea precisamente el periodo acotado por ellos el que constituya el eje cronológico del presente trabajo, aunque, evidentemente, la trascendencia que se les atribuye no deje de estar condicionada por un componente esencialmente retórico, empezando por el hecho de que la consecución del título de doctor no es sólo un

* Este trabajo forma parte de la actividad científica desarrollada por el Grupo Consolidado CEMA (Universidad de Zaragoza), dirigido por J. Ángel Sesma Muñoz y financiado por el Gobierno de Aragón y el Fondo Social Europeo (cema.unizar.es); y el Proyecto de Investigación HAR2012-32931 (I+D+i, Ministerio de Economía y Competitividad), cuyo investigador principal es Carlos Laliena Corbera. 
acontecimiento singular en la carrera de cualquier investigador, sino, sobre todo, el resultado de toda una etapa de formación cuyas raíces, en no pocos casos, se hunden hasta la primera juventud del doctorando. Y otro tanto podría decirse del segundo de los momentos señalados, la jubilación académica, que suele ser celebrada, las más de las veces, no tanto porque conlleve el retiro de la vida activa, sino precisamente por facilitar a quienes la alcanzan la posibilidad de seleccionar los temas y determinar los tiempos que marcarán, en el futuro, el ritmo de su propia actividad investigadora. Así ocurre, al menos, en aquellos casos en los que el oficio de historiador se ejerce por vocación y la pasión por la Historia se cultiva cada día, haciéndolo además de la única manera realmente eficaz, es decir, mediante el trabajo y el esfuerzo continuados. La carrera del profesor Sesma constituye un ejemplo paradigmático de este modus operandi, como tendremos ocasión de comprobar a lo largo de las siguientes páginas.

\section{Trayectoria académica}

A nivel profesional, José Ángel Sesma forma parte de ese grupo de profesores universitarios que, tras haber concluido sus tesis de doctorado entre los años sesenta y setenta del siglo pasado, ingresaron en los cuerpos docentes de la Universidad española a caballo de la dictadura y la democracia, en un periodo de transición política pero también, y en gran medida, científica y académica. Desde entonces hasta ahora, han pasado cinco décadas en las que la Universidad ha cambiado mucho, como también lo ha hecho la sociedad a la que se debe y de la que forma parte, convirtiéndose progresivamente en una institución mucho más amplia y más densamente conectada con otros espacios de investigación y creación cultural, aunque, sin duda, este tipo de vínculos continúen siendo, en muchos sentidos, notoriamente deficitarios. Desde un punto de vista mucho más concreto, en lo que concierne al área de Historia Medieval, el profesor Sesma se inscribe dentro de una generación de historiadores que accedió al grado de doctor entre 1965 y 1978, y que, prácticamente al mismo tiempo, se integró con determinación en los complejos espacios de la producción científica para aportar importantes novedades teóricas y metodológicas, en gran medida inspiradas por las tendencias historiográficas vigentes por aquel entonces en otros países europeos, principalmente Francia, Inglaterra e Italia. 
Entre los miembros de esa generación, por orden de obtención del doctorado, cabe destacar a José-Luis Martín Rodríguez (1965), Julio Valdeón (1965), José Ángel García de Cortázar (1965), Miguel Ángel Ladero Quesada (1967), Juan Ignacio Ruiz de la Peña (1967), Manuel González Jiménez (1971), Juan Carrasco Pérez (1972), Antonio Collantes de Terán (1974), Manuel Sánchez Martínez (1974), José Enrique López de Coca (1974), Emilio Cabrera Muñoz (1975) y, claro está, nuestro protagonista, José Ángel Sesma Muñoz (1976). Todos estos historiadores, junto con algunos de sus primeros discípulos, fueron artífices de la renovación experimentada por el medievalismo español en ese contexto de transición que acabamos de señalar, desempeñando, desde entonces, una intensa labor académica e investigadora, siempre desde la vanguardia de la profesión. Sería poco honesto y, desde luego, no es nuestra intención, atribuir a unos pocos autores el protagonismo de todo un complejo proceso de cambio en las formas de concebir y elaborar el conocimiento histórico de tema medieval, máxime si tenemos en cuenta que aquél se produjo en un contexto de creación de nuevos centros de investigación y ampliación de los ya existentes, un fenómeno que significó el ingreso de muchos otros medievalistas en los espacios académicos y multiplicó las oportunidades para el desarrollo de la disciplina. No obstante, menos aún lo sería, al menos en nuestra opinión, regatear un ápice del reconocimiento que merece este grupo de historiadores, por haber sabido realizar, hace ya varias décadas, aportaciones sustancialmente originales al panorama historiográfico de nuestro país y haber impulsado, desde entonces, fructíferas líneas de trabajo, pasando a ejercer una suerte de «jurisdicción de la investigación», en palabras del profesor García de Cortázar (2011: 29), que en no pocos casos se ha prolongado hasta el presente.

La influencia de los autores citados sobre el medievalismo español de las últimas décadas ha quedado suficientemente contrastada en la historiografía más reciente, puesto que, coincidiendo bien con su jubiliación del profesorado (para la mayoría de los historiadores citados) o bien con su fallecimiento (en el caso de José Luis Martín), todos ellos han sido objeto de sentidos homenajes y profundas semblanzas historiográficas, en las que distinguidos especialistas han puesto de manifiesto el valor de sus respectivas obras y, sobre todo, la relevancia de su magisterio sobre las generaciones posteriores. Más allá de las diferencias observadas en cuanto a la elección de los temas, la selección de las fuentes y la resolución de los problemas estrictamente científicos, todos ellos comparten una serie de características muy concretas en cuanto a su for- 
ma de investigar y escribir Historia, que aquí reuniremos en torno a cinco grandes rasgos.

El primero y, tal vez, el más evidente de ellos se encuentra en el ámbito de la formación, puesto que todos los miembros de esta generación de historiadores obtuvieron su titulación universitaria en el marco de ambiciosos planes de estudio de carácter generalista, lo que favoreció que, desde la fase inicial de sus respectivas trayectorias académicas, incorporaran a sus líneas de investigación referencias procedentes de disciplinas como la Geografía, la Antropología o el Derecho, por citar tan sólo tres de las más representativas (García de Cortázar, 2011: 43-46; Peña Bocos, 2012: 17-18). Como consecuencia directa de ello, muchos de estos historiadores manifestaron en su práctica docente una notable preocupación por la teoría y por los problemas de orden metodológico, ya desde las propias clases de licenciatura, pero, muy especialmente, en la fase de formación predoctoral de sus alumnos (Val Valdivieso, 2009: 8; Peña Bocos, 2012: 11-21; Borrero Fernández, 2014: 21). En tercer lugar, no es posible obviar la menos visible aunque siempre relevante labor de organización académica, que incluyó desde la dirección de departamentos universitarios hasta el diseño de planes de estudios y, en algunos casos, la configuración de algunas Universidades de nueva creación, surgidas en paralelo a la creación del actual modelo autonómico de ordenación estatal (Solórzano Telechea, 2012: XXII-XXIII; Aznar Vallejo, 2014: 13-14). La permanente disposición para la búsqueda, selección y edición crítica de fuentes documentales constituye el cuarto de los rasgos que nos gustaría subrayar aquí, una tarea que se ha concretado no sólo a través de publicaciones propias, sino también mediante la dirección de colecciones documentales fundamentales para el conjunto de los territorios peninsulares (Carrasco Pérez, 2012: 22; Peña Bocos, 2012: 24; Borrero Fernández, 2011: 23-24). Y, en quinto lugar, destacaremos una última cualidad común a todos ellos, como también a muchos de sus discípulos: la defensa de la ciencia histórica frente a los relatos sobre el pasado construidos en los grandes espacios de poder, ya sea éste de carácter político, económico o mediático (Val Valdivieso, 2009: 9-10; García de Cortázar, 2011: 35-36; Aznar Vallejo, 2014: 17).

Este análisis, efectuado lógicamente desde la perspectiva del presente y en términos de larga duración, no estaría completo sin prestar atención a aquellos factores que han condicionado la actividad profesional de esta generación de medievalistas a lo largo del tiempo. Para dar cuenta de ello, en lo que respecta a la trayectoria académica de Ángel Sesma, es preciso cambiar de registro y 
adoptar un discurso de tipo biográfico cuyo inicio, necesariamente, ha de situarse en la etapa de formación universitaria de nuestro protagonista. Fue en el verano de 1968, cuando, a la edad de veintidós años y según sus propias palabras, el profesor Sesma tomó conciencia de su vocación de historiador y decidió matricularse en la Facultad de Filosofía y Letras de su ciudad, Zaragoza. La decisión llegaba tras una experiencia universitaria de dos cursos en disciplinas técnicas, transcurridos primero en Madrid y después en la Facultad de Ciencias de Zaragoza. Que la rentabilidad académica de esta etapa fuera mínima, como él mismo reconoce, no fue incompatible con el hecho de que esos dos años proporcionaran algunas de las experiencias formativas más importantes de su juventud. La vida en Madrid, la toma de contacto con las singularidades de la capital a mediados de la década de los sesenta, la inmersión en la literatura y, muy especialmente, la poesía, proporcionaron unas bases culturales muy heterogéneas pero a la vez extraordinarimente útiles para iniciar una carrera tan amplia en contenidos y problemáticas como era entonces Filosofía y Letras (Sesma, 2013c: 32-33).

$\mathrm{Al}$ acabar el tercero de los cinco cursos de la licenciatura, el último dedicado a las materias denominadas comunes, Sesma optó por escoger el itinerario de Historia Medieval. Y, como consecuencia de aquella decisión, comenzó su relación con una de las personas que han marcado más directamente su propia trayectoria, el profesor José María Lacarra, catedrático de Historia Medieval en la Universidad de Zaragoza desde 1941 hasta su jubilación en 1977. Así, al comienzo de aquel año lectivo 1971-1972, el entonces estudiante Ángel Sesma obtuvo una beca de colaboración, en la primera de las convocatorias de este tipo de ayudas que se publicaron en España y, gracias a ello, pudo incorporarse como colaborador al modesto equipo que dirigía el profesor Lacarra en el Departamento de Historia Medieval, donde le acompañaban entonces María Luisa Ledesma, como profesora adjunta, y tres investigadores predoctorales (FPI): Isabel Falcón, Carmen Orcástegui y Juan Fernando Utrilla (Sesma, 2013c: 34).

El magisterio de José María Lacarra actuó sobre la inicial vocación de nuestro protagonista de modo decisivo, pues sirvió para forjar un modo particular de concebir tanto la investigación como la tarea docente en el ámbito universitario. Las clases de la asignatura «Instituciones Medievales», que impartía entonces Lacarra, proporcionaron el modelo que, años después, puso en práctica el propio Sesma en las materias optativas o de especialidad. Grupos de alumnos reducidos, explicaciones breves pero complejas y cargadas de su- 
gerencias, que daban paso a la lectura y análisis de documentos, a partir bien de transcripciones o bien de reproducciones de la fuente original (Sesma, 1998a: 73-74; 2013c: 34-35). Esa era la dinámica que regía las clases de «Historia económica y social de la Edad Media» mientras la impartió el profesor Sesma y que yo cursé, con él, en el año académico 2002-2003. El programa de la asignatura incluía nueve temas que recorrían los cambios económicos y sociales experimentados por la sociedad feudal desde la Antiguiedad tardía hasta el Renacimiento, con una mención especial, en el último de ellos, a la incidencia de dichos cambios en el ámbito del reino y la Corona de Aragón. Junto al seguimiento de las clases, en las que las intervenciones del alumnado y los debates eran habituales, y la intensidad en la preparación del examen, recuerdo que en aquel curso se nos propuso la lectura y comentario por escrito de uno o dos libros de la bibliografía incluida en el programa. Mis elecciones, entonces, fueron Niveles de vida en la Baja Edad Media de Chris Dyer (Dyer, 1989) y Europa 1400. La crisis de la baja Edad Media, de Ferdinand Seibt y Winfried Eberhard (Seibt y Eberhard, 1993).

$\mathrm{Al}$ releer hoy los materiales trabajados en aquella asignatura y, sobre todo, los apuntes tomados durante las explicaciones y análisis de los textos, uno no puede evitar hacer comparaciones con nuestro presente y llegar a dudar, muy mucho, de que las reformas educativas más recientes hayan aportado algo realmente sustancial al sistema. Máxime si tenemos en cuenta que el modelo docente que acabo de señalar no fue, ni mucho menos, una creación original de José María Lacarra, ni tampoco una singularidad en la Universidad de su época. De hecho, se trataba de una metodología muy extendida entre buena parte de los profesores universitarios más relevantes de la primera mitad del siglo xx en España, aunque, significativamente, ninguno de ellos sea recordado hoy por sus aportaciones a la Historia de la Educación, sino únicamente por sus investigaciones en el ámbito de la Historia Medieval. El propio Lacarra, en su aportación al Homenaje al profesor Claudio Sánchez-Albornoz (Buenos Aires, 1964), evocaba las clases recibidas del maestro abulense destacando, precisamente, la relevancia que el manejo de las fuentes y la discusión con el alumnado ocupaban en ellas, y señalando, además, que el método había sido introducido en la Facultad de Letras de Madrid por Eduardo de Hinojosa, de quien el propio Sánchez-Albornoz había sido, a su vez, discípulo (Ruiz de la Peña, 2009: 217).

La experiencia adquirida en los últimos cursos de licenciatura se vio reforzada además con las primeras incursiones en los archivos aragoneses, espe- 
cialmente el de protocolos notariales de Zaragoza y el de la Diputación, donde se conservan los restos del antiguo Archivo del Reino de Aragón. Los materiales obtenidos en el segundo de ellos permitieron a José Ángel Sesma plantear y redactar su tesis de licenciatura, tarea en la que contó con la ayuda del profesor Ángel San Vicente, del Departamento de Paleografía, a quien conocía ya de su época en el Bachillerato. El trabajo resultante llevó por título Relaciones epistolares de la Diputación del Reino de Aragón (1484-1486) y fue defendido en septiembre de 1973, obteniendo con él la máxima calificación y el Premio Extraordinario de Licenciatura. De aquella investigación nació el proyecto de tesis doctoral con el que obtuvo la beca que le permitió incorporarse, ya como investigador, al departamento de Historia Medieval de la Universidad de Zaragoza, con la tutela académica de José María Lacarra, en enero del año siguiente. El título con el que se presentó el proyecto fue $L a$ Diputación del Reino de Aragón en la época de Fernando II. Apenas tres años más tarde, el 20 de noviembre de 1976, se celebró el acto de defensa de la tesis y, al año siguiente, fue publicada en Zaragoza por la Institución «Fernando el Católico» (Sesma, 2013c: 35).

Durante la preparación de su tesina y, posteriormente, de su tesis, el profesor Sesma tomó contacto con un tipo de fuente inexplorada entonces y que todavía hoy está muy lejos de haber sido agotada por los investigadores. Se trata de los volúmenes generados como consecuencia de la administración del impuesto de las generalidades, tasa aduanera impuesta por las Cortes aragonesas a partir de 1364 y gestionada por una comisión de diputados nombrada por la asamblea. Los registros conservados son, en realidad, una pequeña parte del total emanado durante todo el tiempo de vida de la institución y se concentran, además, en las décadas centrales del siglo XV, pero la información recogida en ellos (mercancías en circulación, cantidades y precios, mercaderes...) y, sobre todo, las posibilidades que ésta abría para desarrollar temas de historia económica terminaron por orientar, durante décadas, buena parte de los objetivos científicos perseguidos por Ángel Sesma.

El enorme potencial de los volúmenes de las generalidades comenzó a cobrar sentido práctico con motivo de la asistencia, como borsista, al VI Corso di alta specializzacione in Storia Economica, en el Istituto di Storia Economica Francesco Datini de Prato, entre septiembre y diciembre de 1973. Allí, el joven Sesma fue alumno de Federigo Melis, cuya obra había comenzado a leer antes de aquella experiencia y a quien, como ha señalado Carlos Laliena, podemos identificar como el segundo de sus grandes maestros, junto a José 
María Lacarra (Laliena, 2013: 19-20). Además del historiador italiano, en aquella edición del curso participaron también Fernand Braudel, Jean Favier, Hugo Tucci y Aldo di Madalena, cuyas lecciones recuerda hoy como «una inmensa ventana por donde entró la luz y el aire nuevo» (Sesma, 2013c: 36). A partir de entonces, la relación con la historiografía italiana de tema económico y, particularmente, con toda la actividad científica promovida por el Istituto Datini, ha sido una constante en la carrera del profesor Sesma y, al mismo tiempo, de no pocos de sus compañeros y discípulos. De hecho, acudir al Datini al menos en una ocasión terminó convirtiéndose, para los estudiantes de doctorado de la Universidad de Zaragoza, en una norma que todavía hoy se cumple, a pesar de que el formato del encuentro se haya visto muy modificado en los últimos años.

El intenso trabajo de aquella etapa de formación dio sus frutos más tempranos en 1976, año en el que, además de concluir y defender su tesis doctoral, como ya hemos indicado, Ángel Sesma publicó sus primeros artículos científicos, entre los que cabe destacar un estudio titulado «Las generalidades del reino de Aragón. Su organización a mediados del siglo XV», que vio la luz en el Anuario de Historia del Derecho Español y que se convirtió muy pronto en un clásico de la materia (Sesma, 1976a). Al año siguiente, junto a la publicación de la tesis, aparecieron también otros dos estudios dedicados al comercio de exportación de trigo, aceite y lana desde Aragón, elaborados a partir de la información obtenida en los citados volúmenes de las generalidades (Sesma, 1977b; y Sesma, Sarasa, 1977d). Todo aquel bagaje constituyó el punto de partida para un proyecto de investigación que, con la financiación obtenida a través de una beca de la Fundación Juan March, concedida en 1978, dio lugar a la publicación de dos obras de referencia: Transformación social y revolución comercial en Aragón durante la baja Edad Media y Léxico del comercio medieval en Aragón (siglo XV), este último en colaboración con Ángeles Líbano (Sesma, 1982a y 1982b). De esta forma, quedaban asentadas las bases que iban a permitir al medievalismo aragonés desprenderse de no pocos tópicos heredados del pasado y aproximarse a la Historia económica del Aragón bajomedieval con un arsenal teórico y metodológico completamente renovado, plenamente operativo y en sintonía con el contexto historiográfico internacional.

En paralelo al desarrollo de esta importante actividad investigadora, Sesma afrontó también el reto de consolidar su carrera universitaria, preparando para ello la oposición al cuerpo de profesores adjuntos, un perfil creado en 1976 que se mantuvo vigente hasta ser sustituido, en 1983, por la figura de los titu- 
lares de Universidad. Tras aprobar la oposición, el 15 de enero de 1981 tomó posesión de la plaza en la Universidad de Zaragoza y en ella permaneció hasta que, en 1987, obtuvo también por oposición la cátedra de Historia Medieval de la Facultad de Geografía e Historia de Lérida, perteneciente entonces a la Universidad de Barcelona. Tres años después, en 1990, regresó a la Universidad de Zaragoza al obtener mediante una nueva oposición la cátedra de Historia Medieval que, por entonces, había dejado vacante Antonio Ubieto, tras su jubilación ese mismo año, y que anteriormente había ocupado José María Lacarra, hasta la suya en 1977 (Sesma, 2013c: 38-39).

Entre tanto, fue transcurriendo la década de 1980, un periodo caracterizado por la ampliación de los estudios históricos en España a todos los niveles. La construcción de un nuevo Estado democrático, a partir del legado de la dictadura franquista, durante la transición, había significado, entre otras cosas, la descentralización de la administración territorial y, con ello, el reconocimiento en el espacio público de una pluralidad no sólo de entidades políticas, las Comunidades Autónomas, sino, sobre todo, de otras tantas identidades culturales, una parte de las cuales pasó a contar, además, con un respaldo formal expresado mediante la categoría de «nacionalidad histórica», incluida en la Constitución de 1978. Pero, más allá de formulismos jurídicos, lo cierto es que las políticas culturales de las nuevas instituciones democráticas, desde los gobiernos autonómicos a los ayuntamientos, no fueron muy diferentes y en todas partes incluyeron una actuación decidida en busca de una Historia propia (Rivière, 2000; García de Cortázar, 2009a: 347-352).

La llegada al poder de grupos políticos silenciados por la dictadura fue un factor decisivo en este proceso, como también lo fue la existencia de una notable demanda social que exigía discursos culturales alternativos a la visión tradicional difundida por el régimen franquista. Si en el ámbito más estrictamente científico, es decir, en las obras de origen y destino preferentemente universitarios, había existido desde tiempo atrás una cierta heterogeneridad de visiones sobre el pasado, que en no pocos casos para nada coincidían con los principios del régimen (Marín Gelabert, 2005: 283-303), en el terreno de la divulgación no sucedía lo mismo y ahí fue donde las instituciones actuaron con mayor decisión. El resultado más evidente de todo ello fue el incremento del número de editoriales públicas (diputaciones y juntas provinciales, centros de estudios locales y/o comarcales, fundaciones...), que no sólo asumieron la responsabilidad de divulgar el conocimiento histórico, sino que terminaron por consolidar los cauces académicos sobre los que iba a discurrir la investigación durante 
décadas. Asimismo, no hay que olvidar que las Cajas de Ahorros contribuyeron muy activamente al desarrollo de estas políticas culturales, mediante la financiación de muchos de estos trabajos a través de su obra social.

La producción histórica generada en este contexto fue, no hará falta insistir en ello, muy desigual, ya que junto a obras muy forzadas en cuanto a sus parámetros e inverosímiles en sus contenidos, aparecieron otras muchas presididas por el rigor científico y que vinieron a colmar importantes lagunas historiográficas (Pasamar, 2004: 364-372). Merece la pena citar, en este punto, la opinión que manifestaba, en 1990, el propio Ángel Sesma sobre el desarrollo de los estudios históricos en su Comunidad Autónoma entre 1977 y 1988, en el marco de unas jornadas dedicadas a analizar el Presente y futuro de la Historia Medieval en España:

La salud de la investigación - alta y, sobre todo, no muy alta - medieval en Aragón ha sido buena en los últimos diez años. Las líneas seguidas y los resultados apreciados responden a unas inquietudes y unos objetivos bastante acordes con la tradición anterior, aunque las condiciones impuestas por las circunstancias extra-académicas, por llamarlas de alguna forma, pueden modificar negativamente esta buena salud. Por un lado hay un exceso de obras de divulgación, tanto a nivel general, es decir, historias de Aragón, como de los más variados temas, incluso los que difícilmente adminten una síntesis fácil por estar en un nivel de investigación todavía incipiente, y que en ocasiones recogen y perpetúan errores y falsas interpretaciones. Las concesiones a la galería, política o comercial, pueden llegar a ser preocupantes.

Por otra parte, aunque resulta doloroso admitirlo porque somos todos responsables, se está llegando a la obsesión por la publicación, por alcanzar cada vez mayor número de títulos publicados y mayor número de páginas cobijadas bajo cada título, sin importar la calidad ni la novedad, sin que la reflexión y la madurez se tengan en cuenta. Quizá por ello se puede advertir un claro abandono de los temas no aragoneses y de los estudios de alta Edad Media, que exigen un tratamiento más riguroso, unos conocimientos más especializados y, en definitiva, obligan a un mayor esfuerzo para unos resultados mucho menos espectaculares y vendibles; en su lugar se tiende a practicar el localismo a todos los niveles, el recurso a la divulgación sin nuevos planteamientos y el abandono de la línea de invenstigación, que es sustituida por el tema, múltiple y cambiante en función de coyunturas oportunas, que nunca llega a profundizarse. (Sesma, 1990a: 113)

En el plano más personal, la década de 1980 significó una progresión notable en las líneas de investigación iniciadas durante la elaboración de la tesis doctoral y la etapa inmediatamente posterior. Así, al estudio de la Diputación a finales del Medievo y a los primeros trabajos dedicados a lo que podemos 
denominar el balance comercial del reino de Aragón en el siglo Xv, les siguieron una serie de artículos que rápidamente se convirtieron en obras de referencia para un gran número de investigadores. Nos referimos, concretamente, al ciclo dedicado a los orígenes de la Diputación del General, la configuración del sistema de aduanas y la nueva fiscalidad de Estado controlada por las Cortes del reino (Sesma, 1983a, 1987b, 1988a y 1992b, entre otros). Por otra parte, desde el punto de vista de la Historia del comercio, llegaron entonces algunas aportaciones de gran repercusión internacional, especialmente en el ámbito italiano. Se trata de las dedicadas al estudio de algunas grandes compañías de comercio, así como a las relaciones comerciales directas entre Aragón y el norte Italia en el siglo XV (Sesma, 1985a y 1985b). Asimismo, la implantación y primeros pasos del tribunal de la Inquisición, en época de Fernando II, recibió también una atención específica que incluyó la edición de una amplia colección documental (Sesma, 1987a y 1989b).

La obtención de la cátedra de Historia Medieval en la Universidad de Zaragoza, en 1990, significó el comienzo de una nueva etapa, en la que comenzaron a tomar forma importantes proyectos colectivos y actividades científicas cada vez más ambiciosas. La primera de ellas, en orden cronológico, fueron los Seminarios Internacionales de Doctorado, que Ángel Sesma dirigió entre 1991 y 2007, cuyo objetivo principal consistía en ofrecer a los estudiantes e investigadores de la Universidad un foro donde escuchar a especialistas nacionales e internacionales en los más diversos temas, debatir con ellos y completar, en definitiva, su formación. En estos encuentros participaron ochenta y cuatro investigadores invitados, y los resultados se publicaron en doce volúmenes (Laliena, 2013: 28). Prácticamente al mismo tiempo, se puso en marcha también un evento científico de una escala notablemente mayor y que iba a convertirse, en seguida, en uno de los referentes historiográficos a nivel europeo. Se trata de la recuperación de las Semanas de Estudios Medievales de Estella, que habían sido creadas por José María Lacarra a comienzos de los sesenta y se habían celebrado anualmente, de forma ininterrumpida, entre 1963 y 1980. La posibilidad de retomar las Semanas surgió de una propuesta realizada conjuntamente por Juan Carrasco y el propio Ángel Sesma, a la que en seguida se sumaron José Ángel García de Cortázar, F. Javier Fortún y Ángel Martín Duque, como miembros de un comité científico en el que se han integrado también, posteriormente y en diferentes etapas, Juan Ignacio Ruiz de la Peña, Pascual Martínez Sopena, José Ramón Díaz de Durana, Eloísa Ramírez, Jaume Aurell y Philippe Sénac (Martín Duque, 1999; Laliena, 
2013: 29). Con el respaldo del Gobierno de Navarra, a través de la Institución Príncipe de Viana, la primera edición de esta segunda época de las Semanas de Estella estuvo dedicada al tema Viajeros, peregrinos y mercaderes en el Occidente Medieval y se celebró, como el resto, en el verano de 1991. Desde entonces, se han sucedido veinticuatro Semanas más y ya ha sido anunciada la próxima, que tendrá lugar en 2016.

El impulso otorgado por las instituciones autonómicas y las Cajas de Ahorros a la producción de obras de Historia durante los años ochenta, con las singularidades ya comentadas, continuó en líneas generales durante la década siguiente y, ya por inercia o ya por verdadero convencimiento de sus respectivos responsables, se mantuvo hasta el estallido de la crisis económica en 2008. De este modo, la comunidad científica ha podido disponer, de forma más o menos continuada, de medios con los que contar a la hora de acometer los propios proyectos, aunque, al mismo tiempo, ha tenido que responder también a demandas e iniciativas concretas emanadas de las distintas administraciones públicas. Como consecuencia de esta dinámica, en las últimas décadas se han puesto en marcha ciclos de conferencias, exposiciones y todo tipo de eventos culturales, dedicados, casi siempre, a conmemorar alguno de los numerosos lugares de memoria que conviven en el espacio público. Pero, sobre todo, se han llevado a imprenta y se han puesto en circulación una serie de obras que, por sus características formales y su contenido, difícilmente habrían visto la luz en el marco estrictamente universitario ni, seguramente, tampoco en el ámbito de las editoriales privadas.

Con la perspectiva que da el paso del tiempo, no es difícil distinguir entre toda esa marea editorial las publicaciones concebidas con el propósito de hacer aportaciones significativas al conocimiento histórico de aquellas que, entonces y ahora, no son más que fruto del impresionismo mediático y de las directrices del mercado. Frente a esas «formas de histeria -que no Historia- de masas», según la brillante expresión de Michael Ignatieff (Aróstegui Sánchez, 2004: 344), la labor de Ángel Sesma ha respondido siempre a una ética profesional basada en el rigor teórico y metodológico, demostrando que la ciencia histórica puede y debe entrar en el espacio público sin renunciar por ello a la complejidad y a la solidez que le son propias. Con este convencimiento, el profesor Sesma ha participado en iniciativas editoriales de amplio calado social y cultural, muchas veces como director de las mismas y otras en colaboración con otros investigadores. Entre los primeros trabajos de este tipo, cabe destacar la Historia de la ciudad de Logroño, en cinco volúmenes, publicada 
en 1995, que Ángel Sesma dirigió y para la cual contó con autores como Philippe Sénac, José Ángel García de Cortázar, Pascual Martínez Sopena, Javier García Turza, Manuel González Jiménez, Anthony Goodman, Angus Mackay, Ernesto García Fernández y José Ramón Díaz de Durana, entre otros (Sesma, 1995a). Y, con un origen muy similar, es preciso señalar también el amplio trabajo sobre regadío, sociedad y poder realizado en colaboración con Carlos Laliena y Juan Fernando Utrilla, que se publicó dentro de un estudio de carácter regional sobre la cuenca del río Aguasvivas, en 1996 (Sesma, Laliena, Utrilla, 1996c).

Una mención especial merece el libro Un año en la Historia de Aragón. 1492, coordinado por Ángel Sesma y cuya autoría compartió con Ángel San Vicente, Carlos Laliena y María del Carmen García Herrero. Esta obra, publicada en 1992, tenía por objetivo «presentar cómo viven, se organizan, trabajan, gozan y sufren, se relacionan, aman y mueren los aragoneses de 1492» (Sesma et al., 1992f: 23). Para responder a tan ambicioso propósito, los autores elaboraron un texto coral escrito en tono literario, casi poético, donde el ritmo de la narración viene marcado por las voces de los aragoneses de finales de la Edad Media, tomadas directamente de los documentos y organizadas conforme a una estructura acorde con el espíritu de la época:

\footnotetext{
Para dar forma a la narración optamos por tomar prestada la estructura de algo que ellos miraban y admiraban: los retablos. Un conjunto de escenas que muestra una panorámica completa, pero que cada una tiene valor por sí; su lectura, sin orden preconcebido, es sencilla y clara (faltaba todavía un tiempo para la llegada del barroco y sus retorcimientos elitistas). Una a una, recorriendo sus «calles» en diagonal, de arriba abajo, o de derecha a izquierda, cada «tabla» de este retablo maravilloso nos pone delante de un pálpito de vida, aragonesa porque de allí son sus actores, pero universal, porque tal es su horizonte sensible. (Sesma et al., 1992f: 23)
}

La dirección de este tipo de proyectos e inciativas basadas en el trabajo en equipo, durante los años noventa, no fue incompatible con la progresión personal en las líneas maestras trazadas hasta entonces e incluso con el desarrollo de temas apenas abordados con anterioridad. Así, a lo largo de aquellos años Ángel Sesma preparó una completa biografía de Fernando II (Sesma, 1992a) y una síntesis sobre la etapa medieval de la Corona de Aragón (Sesma, 2000a), además de otros muchos estudios sobre Historia de las instituciones, el comercio y la fiscalidad de Estado. Entre las novedades correspondientes a aquella época, se encuentran algunos trabajos sobre demografía histórica (Sesma, 
1991c y 1991c) y otros de índole prosopográfica (Sesma, 1991b; y Sesma, Laliena, 1999e), temas que apenas contaban con precedentes directos dentro de su obra (Sesma et al., 1981b; y Sesma, 1986b).

Con la configuración del actual sistema de promoción del conocimiento, basado en convocatorias de Proyectos de I+D+i (principalmente estatales) y grupos de investigación reconocidos por las diferentes administraciones autonómicas, la dinámica de trabajo en equipo sostenida desde 1990 experimentó algunos cambios relevantes. Las novedades, en aquel momento, no llegaron tanto en el plano teórico o metodológico como, sobre todo, en lo que respecta a la duración de los proyectos y la ampliación de los equipos de trabajo. Así, entre finales de la década de 1990 y comienzos de la siguiente, Ángel Sesma asumió la dirección de dos Proyectos de I+D+i consecutivos, dedicados respectivamente a estudiar globalmente la demografía del reino de Aragón en la Baja Edad Media y las sociedades urbanas aragonesas desde un punto de vista prosopográfico. Entre los resultados de aquellos proyectos, cabe destacar la publicación de un grueso volumen titulado La población de Aragón en la Edad Media (siglos XIII-XV). Estudios de demografía histórica (Sesma, Laliena, 2004), en cuya elaboración participaron diez investigadores vinculados al área de Historia Medieval, y la realización de varias tesis doctorales que fueron leídas entre 2004 y 2008 (Sesma, Laliena, Navarro, 2006g).

Pero, sin duda, la novedad más importante entre las introducidas en aquel momento se encuentra en la fundación, en 2002, del Grupo CEMA, que el profesor Sesma ha venido dirigiendo desde entonces como investigador principal. El nombre del grupo está tomado directamente del acrónimo del Centro de Estudios Medievales de Aragón, creado por José María Lacarra en 1941 e incorporado, dos años después, a la estructura del Consejo Superior de Investigaciones Científicas, y que desarrolló una importante actividad hasta 1977 (Sesma, Falcón, 2006h: 261-265; Marín Gelabert, 2007: 48-52). Desde entonces, nuestro protagonista había aguardado la oportunidad de recuperar el centro en el que, de hecho, había dado sus primeros pasos como investigador, posibilidad que, finalmente, cobró forma en el contexto de las convocatorias autonómicas de grupos de investigación. Inmediatamente, la fundación del Grupo CEMA permitió poner en marcha un proyecto de larga gestación, el cual se había convertido en una de las grandes asignaturas pendientes del medievalismo aragonés y, cabría decir, español. Nos referimos a la edición crítica de las actas de las Cortes y parlamentos del reino de Aragón, una empresa de connotaciones faraónicas tanto en lo científico como en lo material y que, 
precisamente por este motivo, había quedado en suspenso en diferentes ocasiones a lo largo de los siglos XIX y Xx. Así, desde 2006, el compromiso de los miembros del Grupo CEMA, junto con el patrocinio económico del Gobierno de Aragón, las Cortes de Aragón e Iber Caja, han contribuido para llevar adelante este gran proyecto, titulado Acta Curiarum Regni Aragonum y que se ha concretado en un total de dieciséis tomos, de los cuales se han publicado ya diez, en quince volúmenes. Al frente del equipo de trabajo, como responsables de la edición, se encuentran el propio Ángel Sesma y Carlos Laliena, miembro también del Grupo desde su fundación. Del sentido y la relevancia que, en opinión de ambos, es portadora la obra, dan buena muestra las siguientes palabras: «Sin exagerar, creemos firmemente que es la mayor aportación que se puede hacer al conocimiento del pasado medieval de Aragón: se trata de miles de páginas de discusiones y acuerdos sobre la fiscalidad, la justicia, la ley y el desenvolvimiento político de todo el reino, los que constituyen las actas de las reuniones». (Sesma, Laliena, 2015e: 20).

Desde la dirección del Grupo CEMA, Ángel Sesma ha impulsado también otra importante labor editorial, que se ha materializado en la aparición de dos colecciones diferentes: Mancuso, que acoge monografías de Historia Medieval con aportación documental; y Garba, que incluye obras de autoría colectiva organizadas en torno a un tema de cierta amplitud. Hasta la fecha, han visto la luz quince tomos en total - siete mancusos y ocho garbas - , en cuya elaboración han participado decenas de autores. La segunda de estas colecciones ha servido, asimismo, para publicar las aportaciones recogidas en las numerosas reuniones científicas organizadas en la última década, entre las que cabe destacar la serie de tres congresos internacionales celebrados en 2008, 2009 y 2010. Bajo el título general La Corona de Aragón en el centro de su Historia (1208-1458), cada una de las reuniones estuvo dedicada a analizar un proceso particular de la Historia medieval de la Corona, dentro de un segmento cronológico que venía acotado por el comienzo del reinado de Jaime I (1208) y la muerte de Alfonso V (1458). Así, el primer encuentro estuvo dedicado a analizar La monarquía aragonesa y los reinos de la Corona (Zaragoza y Monzón, 2008); el segundo se orientó hacia los Aspectos económicos y sociales (Zaragoza y Calatayud, 2009); y el tercero versó sobre El Interregno y el Compromiso de Caspe (Zaragoza, Caspe y Alcañiz, 2010).

El sentido científico de esta iniciativa respondía a un enfoque historiográfico ampliamente vindicado por Ángel Sesma, tanto en su obra de autoría individual como en aquellos trabajos y proyectos que ha dirigido durante toda su 
carrera: la necesidad de plantear la Historia medieval de la Corona de Aragón como un conjunto de conexiones políticas, económicas, sociales y culturales trazadas entre los diferentes Estados que formaron parte de la misma, ya que la trayectoria de cada una de las partes no puede entenderse, al menos no en sus aspectos clave, sin contar con el resto. Ya en 1988, en el contexto de las jornadas dedicadas al Presente y futuro de la Historia Medieval en España, a las que hemos hecho referencia más arriba, Sesma había planteado esa necesidad como un deseo para el futuro, pensando sobre todo en la investigación que, en adelante, se iba a desarrollar desde la Comunidad aragonesa (Sesma, 1990: 128). Con el ciclo de congresos dedicados a La Corona de Aragón en el centro de su Historia, participaron también de dicho propósito un elenco de especialistas en la Historia medieval de Cataluña, Valencia, Mallorca, Cerdeña, Nápoles, Sicilia, Portugal, Castilla, Francia y, por supuesto, del antiguo reino de Aragón. En la presentación del segundo de los volúmenes, él mismo expresaba este planteamiento con las siguientes palabras:

Una de las más luminosas experiencias que puede obtenerse al analizar la trayectoria de la Corona es la lógica y coherencia con que sus estructuras, relaciones internas y normas de convivencia se transforman para adaptarse a las sucesivas coyunturas atravesadas, con el fin de que el edificio común se sostuviera útil y beneficioso para el conjunto, teniendo como principal objetivo el mantenimiento de la unión. Esa idea de unidad, enfocada sobre la monarquía y conservada por encima de todo, y el respeto a las identidades, la mayoría de ellas transversales o, para entendernos, trasnacionales, referidas especialmente a los estados peninsulares que formaban la Corona, podía ser la divisa y el principal rasgo de su identidad, si no hubiera sido por los presentismos y la tergiversación que con posterioridad se introdujeron. (Sesma, 2010b: 8)

Toda esta actividad de impulso y dirección de actividades científicas de amplio alcance, que ha venido caracterizando la carrera de Ángel Sesma desde la fundación del Grupo CEMA, ha exigido, claro está, de una implicación directa, demostrada durante innumerables horas de despacho, dedicadas a la planificación y a la resolución de todo tipo de problemas. Pero, evidentemente, su trayectoria en la última década y media no se ha reducido, ni mucho menos, a las tareas propias de la dirección científica. Resulta impensable, de hecho, que una responsablidad de semejante calado pueda llevarse a cabo sin estar al día de la actualidad historiográfica, de las aportaciones más importantes y los debates más recientes, participando activamente de estas dinámicas. En este sentido, durante la última década y media, el profesor Sesma ha de- 
mostrado una capacidad de trabajo continuada, que le ha permitido profundizar en sus grandes líneas de investigación ampliando sus propias perspectivas e incorporando nuevas fuentes primarias. De hecho, puede decirse sin miedo a errar que, durante los últimos años, su proverbial pasión por los documentos no sólo se ha mantenido intacta, sino que incluso ha llegado a incrementarse. Prueba de ello es el impulso de la colección Acta Curiarum Regni Aragonum, a la que ya nos hemos referido, pero además es preciso subrayar que desde 2004 Ángel Sesma ha asumido la dirección técnica de la colección «Textos e instrumentos para la investigación», del Departamento de Historia Medieval, Ciencias y Técnicas Historiográficas y Estudios Árabes e Islámicos de la Universidad de Zaragoza, que cuenta ya con trece tomos publicados. Tres de ellos corresponden a ediciones de su propia autoría (Sesma, 2005a, 2006 y 2010c), mientras que en otros dos más ha participado en colaboración con otros investigadores (Sesma, Abella, 2013e; y Sesma et al., 2015d).

Tres referencias recientes, tomadas de entre una producción que abarca decenas de títulos, nos servirán como muestra de la producción historiográfica de nuestro protagonista en la última década. La primera es una monografía incluida en la colección Mancuso, antes citada, en la que, a partir del atentado sufrido por Fernando II en Barcelona, se ofrece un completo análisis del conflicto que sesgó las relaciones entre la monarquía aragonesa y las oligarquías del principado catalán en el siglo xv. Se trata de Los Idus de diciembre de Fernando II. El atentado del rey de Aragón en Barcelona (Sesma, 2006a). La segunda obra es El Interregno (1410-1412). Concordia y compromiso político en la Corona de Aragón (Sesma, 2011a), en la que lleva a cabo una completa revisión del que, sin duda, fue un periodo clave en el periodo medieval de la Corona, prestando una especial atención a la prosopografía de los grupos dominantes en cada uno de sus territorios y efectuando un minucioso análisis de las fuentes originales (Sesma, 2011c; Sesma, Laliena, Monterde, 2012f). Y la tercera referencia corresponde a un amplio estudio sobre el impacto social e institucional de la Inquisición fundada por los Reyes Católicos en la Corona de Aragón, titulado Fernando II y la Inquisición: el establecimiento de los tribunales inquisitoriales en la Corona de Aragón, 1479-1490 (Sesma, 2013a).

El último de los libros citados nos lleva a un terreno particularmente grato, como es el de los reconocimientos efectuados por compañeros y discípulos, puesto que se trata del texto del discurso leido por Ángel Sesma el 16 de junio de 2013, con motivo de su recepción pública como académico de número de la Real Academia de la Historia. El nombramiento, que se había efectuado por 
unanimidad en octubre del año anterior, significó la culminación de un brillante cursus honorum profesional, justo cuarenta años después de haberlo iniciado. Como es costumbre, la recepción contó con una solemne contestación al discurso, responsabilidad que asumió el profesor Miguel Ángel Ladero Quesada, quien puso la rúbrica con sus palabras a un acto tan especial: «El profesor Sesma forma parte de la generación más joven de los discípulos que tuvo don José María Lacarra de Miguel en la Universidad de Zaragoza. Muchos de los aquí presentes conocimos al profesor Lacarra, que fue destacado académico durante más de quince años, y lo recordamos con respeto y afecto. Un cuarto de siglo después, vuelve a la Academia la historiografía aragonesa personificada en su antiguo discípulo, y lo hace con los mejores títulos que quepa imaginar.» (Ladero, 2013: 187)

Prácticamente al mismo tiempo que se producía el nombramiento como académico, se estaba gestando, en la Universidad de Zaragoza, un homenaje muy particular, promovido en este caso por los profesores José Ángel García de Cortázar y Carlos Laliena. Se trata de la edición, en un único volumen, de doce trabajos elaborados por Ángel Sesma durante toda su trayectoria profesional y publicados en distintas obras, si bien todos ellos están dedicados a analizar las relaciones comerciales sostenidas entre el reino de Aragón y el mundo mediterráneo en los siglos xIV y xV (Sesma, 2013b). La obra está acompañada, además, de una reflexión autobiográfica del propio Sesma, precedida de dos textos, de corte historiográfico, elaborados por los editores, y una larga tabula gratulatoria, en la que figuramos más de un centenar de compañeros, amigos y discípulos. Independientemente de los motivos concretos por los que cada uno de nosotros quisimos participar de aquel homenaje, estoy seguro de que todos coincidiríamos en hacer nuestra la valoración del profesor García de Cortázar, cuando, en su introducción, identificaba a Ángel Sesma como alguien que, en definitiva, ha sabido realizar «el sueño de todo aprendiz de historiador» (García de Cortázar, 2013: 16).

El orden cronológico que hemos seguido hasta aquí y que nos ha permitido sobrevolar, al menos, la trayectoria profesional de José Ángel Sesma, no estaría completo sin hacer una parada en una faceta esencial para un historiador que, como él, ha conseguido orientar ánimos y voluntades colectivas hacia proyectos de largo alcance historiográfico. Me refiero a su función como docente en todos los niveles, tanto en cursos de licenciatura y tercer ciclo como en el terreno más personal de la tutela académica. El simple hecho de recordar que se trata de uno de los dos autores, junto con José Ángel García de Cortá- 
zar, de uno de los manuales de Historia Medieval universal más utilizados en España, desde hace ya casi dos décadas (Sesma, García de Cortázar, 1997f y 2008d), nos ahorrará ahondar mucho más en lo que respecta a su dedicación a las materias propias de licenciatura. Sin embargo, sí me gustaría prestar algo más de atención a su labor como director de trabajos de investigación, que se ha concretado en decenas de tesis de licenciatura y trabajos de DEA, además de las siete tesis doctorales defendidas entre 1987 y $2015 .{ }^{1}$ En un tiempo en el que el diseño curricular amenaza con desplazar a las propias tesis como principal objetivo de los doctorandos, obligándoles a quemar etapas a un ritmo cada vez más acelerado, resulta más necesario que nunca tomar ejemplo de aquellos maestros que, como Ángel Sesma, tratan de estimular en los estudiantes la convicción de que adquirir el hábito del trabajo continuado y la reflexión pausada debería ser el primero de los objetivos de su formación. Una tarea compleja a la que nuestro protagonista nunca ha dado la espalda, demostrando su compromiso mediante la lectura crítica y la corrección detallada de los trabajos en construcción, la discusión de los problemas surgidos durante el proceso y, llegado el momento, el respaldo necesario para que el doctorando elabore sus propias conclusiones.

\section{Itinerarios historiográficos}

El origen de la obra de Ángel Sesma se inscribe en la escuela de medievalistas impulsada por José María Lacarra desde la cátedra de Historia de la Edad Media, Universal y de España de la Universidad de Zaragoza, y que tuvo en el Centro de Estudios Medievales de Aragón (CSIC) un importante soporte material e institucional. En este entorno académico, el profesor Sesma pudo incorporarse a la sólida línea de investigación promovida por Lacarra,

1 Se trata de las tesis de María del Carmen García Herrero, La mujer en Zaragoza en el siglo XV: aportación al estudio de la sociedad urbana aragonesa bajomedieval, 1987; María Jesús Torreblanca Gaspar, Violencia urbana y sus manifestaciones en Aragón en la Baja Edad Media: luchas de bandos y régimen municipal en las ciudades aragonesas (1250-1450), 1993; María Teresa Iranzo Muñio, El concejo de Huesca en la Edad Media. Estructura, funcionamiento y financiación de la organización municipal en la Baja Edad Media, 2004; Juan Abella Samitier, La villa aragonesa de Sos en la Baja Edad Media. Economía, sociedad y manifestaciones de poder, 2007; Susana Lozano Gracia, Las elites en la ciudad de Zaragoza a mediados del siglo XV: La aplicación del método prosopográfico en el estudio de la sociedad, 2008; Mario Lafuente Gómez, La guerra de los Dos Pedros en Aragón (1356-1366). Impacto y trascendencia de un conflicto bajomedieval, 2009; y María Teresa Sauco Álvarez, Actividad económica y transformación social en la ciudad de Barbastro durante la Baja Edad Media, 2016. 
orientada al estudio de las grandes instituciones medievales de Aragón y Navarra, y lo hizo mediante la realización de su tesis doctoral dedicada, como hemos indicado anteriormente, a La Diputación del reino de Aragón en la época de Fernando II. De esta manera, Sesma inciaba el que ha sido su primer gran itinerario historiográfico y que se puede enunciar como una Historia política centrada en el estudio de las instituciones y sus agentes, que le ha llevado a ocuparse fundamentalmente de las dinámicas internas que explican la formación y evolución históricas de las grandes estructuras de poder en la Baja Edad Media. La riqueza de los documentos manejados durante la preparación de su tesis despertó en él, además, un primer interés por el mundo de las relaciones comerciales, que se vio consolidado tras tomar contacto con la potente historiografía económica de los años sesenta y setenta. De este modo, se inciaba entonces la que iba a convertirse en su segunda gran línea de investigación: la Historia económica centrada en la fiscalidad sobre el comercio y, por extensión, en el desarrollo comercial del reino de Aragón en la Baja Edad Media. Asimismo, trabajar sobre las dinámicas institucionales y el mundo de las relaciones comerciales exige, necesariamente, prestar una atención especial a la sociedad, como conjunto cohesionado de grupos y organizaciones, y precisamente este aspecto constituye su tercer gran ámbito de interés historiográfico, concretado en el estudio de aspectos como la demografía o la prosopografía de las sociedades urbanas. Esta clasificación, no obstante, no pretende encuadrar la totalidad de una obra acumulada durante cuatro décadas $-\mathrm{y}$ que, como hemos visto en el apartado anterior, presenta una enorme cantidad de registros - sino, únicamente, servir de guía para apreciar las aportaciones del profesor Sesma a la reciente historiografía de tema medieval en España.

\subsection{Política: las instituciones y sus agentes}

A mediados del siglo xx, varias corrientes historiográficas contribuyeron a la renovación de la Historia política tradicional, heredada de la historiografía liberal decimonónica, mediante la progresiva configuración de un cuestionario que incluía enfoques y problemáticas sustancialmente diferentes a los predominantes hasta entonces. Como consecuencia de ello, la secuencia de personajes emblemáticos y hechos fundamentales en la construcción del pasado nacional fue siendo desplazada progresivamente por aspectos de corte sociológico (organizaciones y estructuras de poder) y antropológico (culturas y discursos políticos) que fueron dotando al estudio de lo político de una complejidad cada vez mayor y, sobre todo, de una cierta sintonía metodológica entre 
las diferentes escuelas de historioradores (Raphael, 2012: 202-204; Nieto, 2003). En España, uno de los autores más precoces en la incorporación de estos planteamientos fue, sin duda, Jaume Vicens Vives, quien supo expresar con claridad meridiana la importancia del estudio de los grupos sociales, sus motivaciones y estrategias, para comprender con precisión el sentido último de las instituciones y entidades políticas (Freedman, Muñoz, 2003: LXII-LXVII). Esta idea arraigó con firmeza en el pensamiento histórico de Ángel Sesma y así lo puso de manifiesto ya en su propia tesis doctoral, desarrollándola posteriormente al estudiar problemas fundamentales en la Historia política de la Corona de Aragón, como son el sistema parlamentario y la compenetración institucional entre los diferentes Estados que la integraron (Sesma, 1977: 2729 y 2013a: 14-15; Laliena, 2013: 17-18).

Este enfoque teórico ha llevado al profesor Sesma a situar en el centro de la arena historiográfica una cuestión esencial, como es la cohesión y funcionalidad política de la Corona de Aragón, en tanto que suma de Estados territoriales definidos por su unidad política en torno a un principio de soberanía común (la monarquía), un rasgo que, como ha demostrado, para nada era incompatible con la diversidad jurídica propia del sistema feudal (Sesma, 1997a, 1999a, 1999c, 2000a, 2005e, y 2010a). Con una visión del pasado equiparable a la gran Historia definida por Fernand Braudel (Braudel, 2002: 23), el profesor Sesma ha interpretado la evolución política de la Corona en los siglos XIV y XV en la larga duración, deteniéndose especialmente en algunas de las coyunturas más relevantes por su influencia sobre el desarrollo histórico general, entre las que cabe destacar el origen y evolución de las Diputaciones del General (Sesma, 1991e: 11-76), la crisis política atravesada a finales del siglo XIV (Sesma, 1991a), el Interregno y el Compromiso de Caspe (Sesma, 1999b, 2011a, 2011b, 2012b) o la guerra civil catalana de mediados del xv (Sesma, 2006a). Una de las aportaciones más relevantes, en este sentido, se encuentra sin duda en el impulso de la edición y estudio sistemático de las actas de Cortes y parlamentos del reino de Aragón, publicadas junto con las correspondientes a las Cortes generales de la Corona, en la colección Acta Curiarum Regni Aragonum, a la que ya nos hemos referido. Actualmente, cuando la investigación sobre el pasado medieval del reino y la Corona de Aragón tiene en la documentación emanada de las Cortes una de sus canteras principales, no está de más recordar que hasta fechas muy recientes carecíamos de una mínima definición de esta tipología documental (Sesma, 1989e) y, lo que es aún más significativo, desconocíamos incluso la existencia de varias 
asambleas que hoy, gracias a esta intensa línea de trabajo, se consideran fundamentales para entender la Historia de Aragón en la Baja Edad Media.

A partir del estudio de la compenetración política entre las entidades que, desde el siglo XII, conformaron políticamente la Corona de Aragón, y de la investigación realizada sobre el reinado de Fernando II, Ángel Sesma ha realizado también valiosas aportaciones a los debates más recientes sobre el sentido de la unión matrimonial entre Fernando II de Aragón e Isabel I de Castilla, y, más concretamente, a la influencia de esta unión sobre las diferentes estructuras de poder vinculadas a su soberanía. Se trata, sin duda, de uno de los grandes temas de la historiografía española, cuyo alcance sobrepasa, con frecuencia, el terreno dominado por medievalistas y modernistas para adentrarse también en el de los especialistas en las edades antigua y contemporánea, especialmente en aquellos casos en los que se trata de inspeccionar los principios simbólicos de la identidad nacional. Desde la óptica de la renovada historia política a la que aludíamos anteriormente, la postura de Ángel Sesma en estos debates se ha orientado a poner en valor el papel de Fernando dentro de las sucesivas coyunturas políticas que se sucedieron a partir de 1469, especialmente en la Corona de Castilla. Un papel que, como ha demostrado, fue determinante para conservar el equilibrio político y la cohesión entre dos espacios de soberanía tan diferentes y abocados, en no pocas coyunturas durante casi cincuenta años, a su disgregación (Sesma, 1992a, 1996b, 2005c, 2006e, 2012a y 2015b: 15-20). No hay que olvidar, en relación con este aspecto, que al filo del año 2000 tuvo lugar en España la penúltima irrupción de la reina Isabel en el dominio público, con motivo del quinto centenario de su muerte (2004), y que este hecho sirvió entonces para reciclar, en el terreno historiográfico, no pocos mitos arrastrados secularmente en torno a su figura (Sesma, 2006e: 521-523; Jover, 1997: 69-73).

Sin apartarnos de la senda marcada por el estudio del reinado de Fernando II, es preciso subrayar también la aportación de Ángel Sesma en torno al origen y puesta en marcha de los tribunales inquisitoriales en la Corona de Aragón. La Inquisicón fue, como él mismo ha puesto de manifiesto, uno de los pocos proyectos desarrollados conjuntamente sobre los dominios de las Coronas castellana y aragonesa - junto con todo lo derivado de la política internacional, la expulsión de los judíos y la reforma de la Iglesia - y su introducción en la primera de ellas formó parte de la estrategia implementada por Fernando II con objeto de fortalecer el poder real en todos sus Estados patrimoniales (Sesma, 2006e: 532-533; y 2013a: 171-184). La medida fue abiertamente con- 
testada por las principales autoridades políticas de la Corona, reacción que dio lugar a una intensa crisis política con graves implicaciones sociales en Aragón, Cataluña y Valencia, cuyo alcance podemos apreciar en términos científicos gracias al trabajo de Ángel Sesma (Sesma, 1987a, 1989b y 2013a).

\subsection{Economía: la fiscalidad y el comercio}

Para muchos de los historiadores españoles formados en las décadas de 1960 y 1970, la Historia económica constituyó la prolongación natural de unos intereses historiográficos vinculados, inicialmente, al estudio del derecho y las instituciones, y heredados de la generación anterior. La recepción de la historiografía francesa asociada a la tradición de Annales fue determinante para ello, ya que por entonces temas como la Historia de las estructuras agrarias o el comercio estaban siendo trabajados en profundidad tanto por medievalistas como, sobre todo, por modernistas (Raphael, 2012: 119-123; Iggers, 2012: 99-103). Junto a las corrientes llegadas de Francia, la investigación dedicada a la Historia de la Corona de Aragón prestó también una atención especial a lo que se estaba haciendo al otro lado del Mediterráneo, en Italia, donde los trabajos de autores como Roberto S. Lopez, Mario Del Treppo o el propio Federigo Melis estaban ofreciendo resultados muy importantes a partir de fuentes similares a las que custodiaban los archivos aragoneses, catalanes y valencianos (Sesma, 2006d: 17-21). Ya hemos mencionado la importancia que la toma de contacto con la obra de Melis y, sobre todo, la estancia en el Istituto Datini, en 1973, tuvieron sobre los intereses historiográficos de Ángel Sesma a partir de entonces, por lo que, en este apartado, nos centraremos únicamente en los resultados más relevantes derivados de esta línea de investigación.

Si el punto de partida era, como hemos visto, una institución global, como la Diputación del General en el reinado de Fernando II, no es difícil entender que la inmersión en el estudio de las relaciones económicas se produjera, para Ángel Sesma, a través de la fiscalidad de Estado. Concretamente, a partir del estudio de las generalidades, una tasa aduanera gestionada por las Cortes y la propia Diputación del reino, y en cuya rentabilidad se basaba la estabilidad económica de la hacienda aragonesa desde la segunda mitad del siglo XIV. Así, su primer trabajo sobre el tema, publicado en Anuario de Historia del Derecho Español en 1976, se convirtió muy pronto, como ya hemos apuntado, en una obra de referencia al poner de manifiesto las conexiones existentes entre el ámbito del poder político y el mercado a mediados del siglo xv, a través de la 
estructura fiscal controlada por la Diputación (Sesma, 1976a). A partir de ahí, Sesma continuó profundizando en esta línea mediante el estudio de las negociaciones desarrolladas en el ámbito parlamentario, donde la monarquía y los grupos dominantes en cada uno de los Estados de la Corona se disputaron el control de una renovada estructura fiscal. La serie de trabajos sobre este tema, publicados en su mayoría durante las décadas de 1980 y 1990 (Sesma, 1979a, 1983a, 1987b, 1988a, 1989a, 1992b, 1997b, 1997e y 2001b; Sesma, Sánchez, Furió, 2008b), se ha convertido en un pilar fundamental sobre el que sustentar los posteriores avances en el ámbito de la fiscalidad y las finanzas públicas tanto en Aragón como en Cataluña y Valencia, como han puesto de manifiesto numerosos autores (Ladero, 2015: 23-33). Asimismo, más recientemente, han tenido su continuación en un pormenorizado análisis de las sucesivas crisis financieras de la hacienda del reino, provocadas por el recurso continuado al endeudamiento censal (Sesma, 2015a).

El conocimiento detallado de las estructuras fiscales del Estado ha sido un elemento fundamental para desarrollar la otra gran vertiente de su interés por el ámbito de la Historia económica, como es el mundo del comercio, sus agentes y los productos objeto de intercambio. Seguramente, su gran aportación en este sentido radica en haber contribuido decisivamente a desterrar la imagen de Aragón como un territorio interior, ligado a un sector primario de corto alcance y ajeno al proceso de comercialización que estaban experimentando, desde el siglo XIII, el resto de Estados del arco mediterráneo. La obra de Ángel Sesma ha proporcionado a la historiografía de tema económico enfoques, argumentos y, lo que no es menos importante, ediciones documentales para demostrar que la evolución del comercio aragonés en la Baja Edad Media estuvo en sintonía con la del resto de los Estados de su entorno y que, además, presentó ciertas singularidades debidas a fenómenos como la especialización o la demanda externa (Sesma, 1982a; Laliena, 2012: 13-14). Cabe destacar al respecto sus estudios sobre la exportación de materias primas y productos básicos, como la lana, el trigo y el aceite, destinados a abastecer los mercados catalanes, valencianos e italianos (Sesma, 1977b, 1985b, 1995b, 1997c, 1997d y 2001a, 2005b y 2010b: 345-362; y Sesma, Sarasa, 1977d) y su trabajo sobre la compañía Torralba, Manariello y Flexas, operativa con capital aragonés y catalán en la primera mitad del siglo xv (Sesma, 1985a). El resultado permite no sólo explicar mejor las propias dinámicas internas del reino de Aragón, sino que resulta imprescindible para entender el sentido de la actividad económica en otros Estados peninsulares y mediterráneos (Iradiel, 1999: 36-49). 
Todos los trabajos inscritos en esta línea de investigación a los que nos hemos referido hasta aquí tienen en común haber sido elaborados a partir de una escala de amplio alcance, es decir, tomando como referencia un perimetro equivalente al reino en su totalidad o a alguna región extensa y bien cohesionada por factores económicos, como es el caso de la vía fluvial del Ebro o el maestrazgo turolense. No obstante, verificar las dinámicas que se desprenden del análisis general a escala local, a través de problemáticas particulares directamente vinculadas con los procesos económicos a medio y largo plazo, ha sido también un objetivo importante a lo largo de la carrera de Ángel Sesma. Las aportaciones realizadas en este sentido son muy numerosas y, entre todas ellas, nos gustaría destacar, por su relevancia, dos: el ciclo de trabajos dedicados a diferentes aspectos del desarrollo comercial de Huesca en el siglo XV, que van desde el mercado de trabajo a las ferias locales (2000b, 2005a, 2011d y 2012d); y un reciente estudio sobre las existencias de una tienda de menaje doméstico zaragozana de finales del siglo XV, en el que se tratan problemas como el consumo y los niveles de vida de la sociedad zaragozana (Sesma, Laliena, 2014d: 23-44).

\subsection{Sociedad: la población y la prosopografía de las sociedades urbanas}

La expresión «Historia social» ha funcionado en el último siglo como un inmenso paraguas capaz de abarcar por sí solo una enorme cantidad de corrientes e intereses historiográficos, cuyo nexo de unión radica, principalmente, en la definición de sujetos históricos colectivos, generalmente alejados de la cúspide del poder político y, en no pocos casos, directamente enfrentados con él. Sin caer en generalizaciones excesivas, resulta evidente que tanto la nueva Historia política como la Historia económica surgieron en Europa de la mano de un interés explícito por grupos sociales que encajaban, más o menos abiertamente, en ese perfil, especialmente cuando se trataba de definir a los agentes que participaron más directamente en los procesos de cambio político y/o económico (Juliá, 2009). Desde esta óptica, no será preciso insistir en que tanto la nueva Historia política como la Historia económica en las que se inscribe aquella parte de la obra del profesor Sesma que hemos analizado hasta ahora se encuentran, por definición, impregnadas de un cierto componente social, que, sin embargo, se encuentra mucho más acentuado en el tercero de los itinerarios que transitaremos aquí. Concretamente, aquél que parte de la demografía histórica y conduce hacia la prosopografía de las sociedades urbanas. 
Para buena parte de los discípulos de José María Lacarra, la demografía histórica ha constituido un método de trabajo ampliamente cultivado, ofreciendo, de hecho, importantes resultados tanto en Navarra como en Aragón. En el caso de Ángel Sesma, el interés por esta temática tuvo su primera parada editorial en un breve trabajo colectivo, de corte metodológico, publicado en 1981 y elaborado en colaboración con M. ${ }^{a}$ L. Ledesma, M. ${ }^{a}$ I. Falcón, C. Orcástegui, J.F. Utrilla y E. Sarasa (Sesma et al., 1981b). Aquella primera inmersión vino seguida, posteriormente, de un estudio dedicado específicamente a la villa de Monzón en los siglos XIII-XV (Sesma, 1986b); otro, sobre la Comunidad de aldeas de Teruel a mediados del siglo XIV (Sesma, 1991c); y un tercero en torno al poblamiento periurbano de Zaragoza a comienzos del Trescientos (Sesma, 2002b). Este bagaje proporcionó la base adecuada para que, en 1998, el profesor Sesma asumiera la dirección del proyecto colectivo que condujo a la publicación del libro La población de Aragón en la Edad Media (siglos XIII-XV), donde, además de incluir algunos trabajos ya publicados anteriormente, se introdujeron valiosas contribuciones inéditas (Sesma, Laliena, 2004a).

Entre las aportaciones contenidas en aquella obra, merece la pena señalar las cuatro grandes conclusiones que él mismo formulaba al cerrar uno de los capítulos de su autoría, titulado «Sobre los fogajes generales del reino de Aragón (siglos XIV-XV) y su capacidad de reflejar valores demográficos». La primera de ellas es la estrecha relación existente entre métodos de recaudación e instrumentos de control sobre la población, en el marco de la construcción del Estado moderno. La segunda, la racionalidad y el consenso que presiden la toma de decisiones en el ámbito fiscal. Como tercera conclusión, Sesma destacaba la tendencia de los distintos grupos de poder a supeditar sus propios intereses al bien común, en el momento de asumir los repartos fiscales. Y, por último, la progresiva sofisticación de los instrumentos empleados en la recaudación, que se refleja en la mayor precisión de los propios fogajes conforme se avanza hacia el final de la Edad Media (Sesma, Laliena, 2004a: 45-49).

De otro lado, el análisis de la población desde un punto de vista cuantitativo ha venido acompañado en la producción histórica de nuestro protagonista de un tratamiento específico sobre las dinámicas sociales de las villas y ciudades aragonesas y, especialmente, del estudio prosopográfico de sus grupos dirigentes. Como resultado de este planteamiento, a partir de comienzos de la década de 1990 ha venido sucediéndose una larga serie de trabajos dedicados al estudio de la red urbana de la Corona de Aragón, con especial atención a las 
conexiones establecidas entre los principales agentes sociales que, con unos rasgos perfectamente comparables, detentaban el poder político y el control económico en cada una de ellas (Sesma, 1991d, 2003b, 2003c, 2006f y 2007c). Como estudios de caso especialmente representativos, cabe destacar los estudios dedicados a las elites de la ciudad de Barbastro (Sesma, 1991b; Sesma, Laliena, 1999e), o el denso análisis sobre el mercado inmobiliario de Zaragoza y la participación en este negocio de grupos influyentes como el clero o los ciudadanos honrados (Sesma, 2007b).

Por último, no quisiera concluir este apartado sin dejar de recordar un libro que ya hemos comentado en la primera parte del trabajo y que constituye, además de un texto extraordinario en cuanto a su valor narrativo, un espléndido ejercicio de Historia social. Me refiero a la obra colectiva Un año en la Historia de Aragón. 1492 (Sesma et al., 1992). Cada uno de sus capítulos proporciona distintas miradas sobre los aragoneses - sin historia, aunque no ánónimos - de finales de la Edad Media, cuyo análisis en profundidad nos trasladaría, a su vez, hacia otros horizontes historiográficos, como son la cultura, la justicia, la fe o la fiesta, por citar, tan sólo, algunos de los muchos terrenos en los que se adentra la obra. Asimismo, tampoco quedaría completo este recorrido por las aportaciones de Ángel Sesma en el ámbito de la Historia social sin mencionar que, a lo largo de su carrera, ha impulsado y dirigido varias tesis doctorales que se inscriben directamente dentro de esta tendencia. Las reflexiones aportadas por él mismo, como director de estos trabajos, a modo de prólogo o presentación de los textos que, finalmente, fueron publicados, permiten comprobar fehacientemente la profundidad de esa «sensibilidad hacia la acción de los agentes sociales» (Laliena, 2013: 18) que, de hecho, atraviesa el conjunto de su obra (Sesma, 1990b: 11-14; 2005f: 13-15; y 2012e: 5-10). Sirva de muestra el siguiente fragmento, tomado de la «Presentación» al libro de Juan Abella Samitier, Sos en la Baja Edad Media. Una villa aragonesa de frontera:

No se puede, ni serviría de nada, reconstruir las vidas de todos los habitantes de un lugar. Tampoco es posible, ni conduce a ninguna parte, intentarlo con la repetitiva trayectoria de los lugares del reino. Ni siquiera en el caso de que existiera suficiente información para hacerlo nos permitiría conocer mejor la historia de Aragón. Sería como confeccionar un mapa del territorio a escala natural (...) Se trata de reunir convenientemente agrupadas las informaciones fragmentadas disponibles, para configurar un tejido de mayor consistencia que permita un reflejo nítido y lo más preciso posible de la sociedad y su evolución en el tiempo, mostrando las peculiaridades de los gru- 
pos y las clases sociales que la componen, las actividades, los recursos económicos, las relaciones políticas, las manifestaciones culturales, sin olvidar las individualidades existentes que muestran capacidades o actuaciones diferentes. (Sesma, 2012e: 7)

\section{Epílogo}

Esta reflexión sobre la trayectoria académica y los itinerarios historiográficos recorridos por José Ángel Sesma concluye aquí, pero su actividad científica continúa. En el momento de dar a imprenta este texto, un nuevo tomo del Acta Curiarum se encuentra en prensa, otro más de la colección Garba (dedicado a los problemas del consumo y la demanda) está en preparación y prosigue, a buen ritmo, la incansable tarea de transcripción de los libros de aduanas del General. Éstos son tan sólo algunos de los proyectos inmediatos de un historiador que, en vísperas de cumplir el trámite administrativo de su jubilación del profesorado, reconoce mirar «con cierta envidia a los que están en la línea de salida, por lo que poseen de ilusión y fe en su futuro». (Sesma, 2013c: 40). Ojalá que esa ilusión y esa fe en el futuro perduren en el ánimo de los estudiantes más jóvenes como han pervivido en el de Ángel Sesma durante todos estos años, porque ello será síntoma de que los historiadores continúan siendo fieles al compromiso contraído con su oficio y con la sociedad.

\section{Referencias bibliográficas}

\section{Obras de José Ángel Sesma Muñoz}

(1976a), «Las generalidades del reino de Aragón. Su organización a mediados del siglo XV», Anuario de Historia del Derecho Español, 46, 395-396.

(1976b), «Carteles de batalla cruzados entre Alfonso V de Portugal y Fernando V de Castilla (1475)», Revista portuguesa de História, 16, 277-295.

(1976c), en colaboración con E. Sarasa Sánchez, Cortes del reino de Aragón. $1357-$ 1451. Extractos y fragmentos de procesos desaparecidos, Zaragoza, Anúbar, 1976.

(1977a), La Diputación del reino de Aragón en la época de Fernando II, Zaragoza, Institución «Fernando el Católico».

(1977b), «El comercio de exportación de trigo, aceite y lana desde Zaragoza, a mediados del siglo XV», Aragón en la Edad Media, I, 201-238. 
(1977c), «Aproximación al estudio del régimen alimentario del reino de Aragón en los siglos XI y XII», en Homenaje a Don José María Lacarra de Miguel en su jubilación del profesorado, Zaragoza, Universidad de Zaragoza, vol. 2, 55-78.

(1977d), en colaboración con E. Sarasa Sánchez, «El comercio de lana por el Ebro hacia el Mediterráneo. El puerto fluvial de Escatrón a mediados del siglo XV», en II Congreso Internacional de Estudios sobre las culturas del Mediterráneo Occidental, Barcelona, Universitat Autònoma de Barcelona, Instituto Universitario de Estudios Medievales 1977, 399-409.

(1979a), «Trayectoria económica de la hacienda del reino de Aragón», Aragón en la Edad Media, 2, 171-202.

(1979b), «Comercio del reino de Aragón en el siglo XV», en Actas de las primeras Jornadas sobre el Estado actual de los estudios sobre Aragón, Zaragoza, Instituto de Ciencias de la Educación (Universidad de Zaragoza), 311-316.

(1980a), «Aragón medieval», en A. Canellas López (dir.), Aragón en su Historia, Zaragoza, Caja de Ahorros de la Inmaculada, 108-188.

(1980b), en colaboración con A. Líbano Zumalacárregui, «Los libros de collidas del General: fuentes para la caracterización del aragonés medieval», en Actas de las segundas Jornadas sobre el estado actual de los estudios sobre Aragón, Zaragoza, Instituto de Ciencias de la Educación, 415-418.

(1980c), en colaboración con R. Ciérvide Martinena, Olite en el siglo XIII: población, economía y sociedad de una villa navarra en plena Edad Media, Pamplona, Institución «Príncipe de Viana».

(1981a), «Instituciones parlamentarias del reino de Aragón en el tránsito a la Edad moderna», Aragón en la Edad Media, IV, 221-234.

(1981b), en colaboración con M. . L. Ledesma Rubio, M. a I. Falcón Pérez, C. Orcástegui Gros, J.F. Utrilla Utrilla y E. Sarasa Sánchez, «Demografía medieval aragonesa», en Estado actual de los estudios sobre Aragón, Zaragoza, Instituto de Ciencias de la Educación (Universidad de Zaragoza), t. II, 529-534.

(1982a), Transformación social y revolución comercial en Aragón durante la baja Edad Media, Madrid, Fundación «Juan March».

(1982b), en colaboración con A. Líbano Zumalacárregui, Léxico del comercio medieval en Aragón (siglo XV), Zaragoza.

(1983a), «La fijación de fronteras económicas entre los estados de la Corona de Aragón», Aragón en la Edad Media, V, 141-163.

(1985a), «La participación aragonesa en la economía de la Corona. Compañías de comercio con capital mixto, en la Baja Edad Media», Anuario de Estudios Medievales, 15, 331-343. Otra edición en Estudios en homenaje a don Claudio Sánchez Albornoz en sus 90 años, Madrid, Instituto de España, 1986, vol. 4, 335-352.

(1985b), «Relaciones comerciales directas entre Italia y el reino de Aragón en la Baja Edad Media», en Aspetti della vita economica medievale. Atti del convegno di studi nel $x$ anniversario della morte di Federigo Melis, Florencia, Università degli studi - Istituto di Storia Economica F. Datini, 1985, 304-320. 
(1986a), «La moneda jaquesa y la emisión de aragoneses de plata», Estudios en homenaje al Dr. Antonio Beltrán Martínez, Zaragoza, Universidad de Zaragoza, 10291040 .

(1986b), «Demografía y sociedad: la población de Monzón en los siglos XIII-XV», Homenaje a José María Lacarra. Príncipe de Viana (Anejos), Pamplona, Gobierno de Navarra, vol. 2, 687-710.

(1987a), El establecimiento de la Inquisición en Aragón (1484-1486). Documentos para su estudio, Zaragoza, Institución «Fernando el Católico».

(1987b), «Estado y nacionalismo en la baja Edad Media. La formación del sentimiento nacionalista aragonés», Aragón en la Edad Media, VII, 245-273.

(1988a), «El sentimiento nacionalista en la Corona de Aragón y el nacimiento de la España moderna», en A. Rucquoi (coord.), Realidad e imágenes del poder. España a finales de la Edad Media, Valladolid, Ámbito, 215-231.

(1989a), «Fiscalidad y poder. La fiscalidad centralizada como instrumento de poder en la Corona de Aragón (siglo XIV)», Espacio, tiempo y forma. Revista de la Facultad de Geografía e Historia de la UNED, 4, 447-463.

(1989b), «Violencia institucionalizada: el establecimiento de la inquisición por los Reyes Católicos en la Corona de Aragón», Aragón en la Edad Media, VIII, 659-673.

(1989c), «Una reina de Aragón en Castilla: el recibimiento castellano a Germana de Foix en 1507, según un testigo aragonés», Anuario de Estudios Medievales, 19 , 681-688.

(1989d), «Instituciones feudales en Navarra y Aragón», I Congreso de Estudios Medievales, Ávila, Fundación «Sánchez Albornoz», 341-371.

(1989e), «¿Podemos plantearnos la publicación de fuentes para el estudio de las Instituciones parlamentarias con los mismos criterios de hace un siglo?», en Istituzioni rappresentative nella Sardegna medioevale e moderna, Cagliari, Consiglio Regionale della Sardegna, 331-338.

(1990a), «La investigación medieval en la Comunidad Autónoma de Aragón», en C. Segura Graíño (ed.), Presente y futuro de la Historia Medieval en España, Madrid, Universidad Complutense, 109-128.

(1990b), «Prólogo», en M. ${ }^{\text {a C}}$ C. García Herrero, Las mujeres en Zaragoza en el siglo XV, Zaragoza, Ayuntamiento, vol. 1, 11-14.

(1991a), «Todos frente al rey (La oposición al establecimiento de una monarquía centralizada en la Corona de Aragón a finales del siglo XIV)», Genese médiévale de l'Espagne moderne. Du refus à la révolte: les resistances, Niza, Université, 75-94. (1991b), «Los Santángel de Barbastro: estructura económica y familiar», Aragón en la Edad Media, 9, 121-136.

(1991c), «La población aragonesa ante la crisis demográfica del siglo xv: el caso de la Comunidad de Teruel, 1342-1385», en V.A. Álvarez Palenzuela, Estudios de Historia Medieval: Homenaje a Luis Suárez, Valladolid, Universidad de Valladolid, 457-471. 
(1991d), «Pequeñas ciudades y grandes villas en el ordenamiento del espacio aragonés», en M. Rigal (ed.), Les sociétés urbaines en France méridionale et en péninsule ibérique au Moyen Âge, París, Éditions du Centre National de la Recherche Scientifique, 37-50.

(1991e), en colaboración con J.A. Armillas Vicente, La Diputación de Aragón, Zaragoza, Oroel.

(1992a), Fernando de Aragón: Hispaniarum rex, Zaragoza, Gobierno de Aragón.

(1992b), «Aduanas y peajes aragoneses con Castilla y Navarra», en Borja y la Raya occidental de Aragón, Zaragoza, Institución «Fernando el Católico», 27-44.

(1992c), «Rasgos precapitalistas en la organización industrial aragonesa (siglo Xv)», Medievalia, 10, 387-402.

(1992d), «El poder real», en A. San Vicente Pino y M. ${ }^{a}$ M. Agudo Romeo, Ceremonial de la consagración y coronación de los reyes de Aragón: ms. $R$. 14425 de la Biblioteca de la Fundación Lázaro Galdiano, en Madrid, Zaragoza, Centro de Documentación Bibliográfica Aragonesa, v. 2, 85-102.

(1992e), «Documentos fiscales medievales: metodología para su explotación científica», Metodología de la investigación científica sobre fuentes aragonesas, Zaragoza, Instituto de Ciencias de la Educación (Universidad de Zaragoza), t. VII, 123-172.

(1992f), en colaboración con A. San Vicente Pino, C. Laliena Corbera y M. ${ }^{a}$ C. García Herrero, Un año en la Historia de Aragón. 1492, Zaragoza, Caja de Ahorros de la Inmaculada.

(1993a), «Cofradías, gremios y solidaridades en la Europa Medieval», Cofradías, gremios, solidaridades en la Europa Medieval, XIX Semana de Estudios Medievales de Estella, Pamplona, Gobierno de Navarra, 17-30.

(1993b), «El Camino de Santiago en Aragón», en J.I. Ruiz de la Peña Solar (coord.), Las peregrinaciones a Santiago de Compostela y San salvador de Oviedo, Oviedo, Principado de Asturias, 87-101.

(1994a) (coord.), Benedicto XIII, el Papa Luna. Muestra de documentación histórica aragonesa en conmemoración del sexto centenario de la elección papal de don Pedro Martínez de Luna (Aviñón, 28 de septiembre de 1394), Zaragoza, Centro de Documentación Bibliográfica Aragonesa.

(1994b), en colaboración con M. ${ }^{a}$ M. Agudo Romeo (eds.), Martín de Alpartil, Cronica actitatorum temporibus Benedicti XIII Pape, Zaragoza, Centro de Documentación Bibliográfica Aragonesa.

(1995a) (coord.), Historia de la ciudad de Logroño, Zaragoza, Iber Caja, 5 vols.

(1995b), «Producción para el mercado: comercio y desarrollo mercantil en espacios interiores (1250-1350): el modelo del sur de Aragón», Europa en los umbrales de la crisis: 1250-1350, XXI Semana de Estudios Medievales de Estella, Pamplona, Gobierno de Navarra, 205-246.

(1995c), en colaboración con C. Laliena Corbera y J.F. Utrilla Utrilla, «Regadíos andalusíes en el valle Medio del Ebro: el ejemplo del río Aguasvivas», en L. Cara 
Barrionuevo y A. Malpica Cuello, Agricultura y regadio en al-Andalus. Sintesis y problemas, Almería, Instituto de Estudios Almerienses, 67-84.

(1996a), «Tecnología y sociedad: las grandes obras públicas en la Europa medieval. Introducción y planteamiento general», en Tecnología y sociedad. Las grandes obras públicas en la Europa medieval, XXII Semana de Estudios Medievales de Estella, Pamplona, Gobierno de Navarra, 19-28.

(1996b), «Ser rey a finales del siglo XV», en E. Sarasa Sánchez (dir.), Fernando II, el rey Católico, Zaragoza, Institución «Fernando el Católico», 109-121.

(1996c), en colaboración con C. Laliena Corbera y J.F. Utrilla Utrilla, «Del mundo andalusí a la Ilustración: regadío, sociedad y poder en el entorno de la gran presa de Almonacid de la Cuba (siglos X-XVIII)», en La presa de Almonacid de la Cuba. Del mundo romano a la Ilustración en la cuenca del río Aguasvivas, Madrid, Ministerio de Obras Públicas, Gobierno de Aragón, 157-308.

(1997a), «La compenetración institucional y política en la Corona de Aragón», Poderes públicos en la Eropa medieval: principados, reinos y coronas, XXIII Semana de Estudios Medievales de Estella, Pamplona, Gobierno de Navarra, 347-372.

(1997b), «Las transformaciones de la fiscalidad real en la baja Edad Media», El poder real en la Corona de Aragón (siglos XIV-XVI), XV Congreso de Historia de la Corona de Aragón, Zaragoza, Gobierno e Aragón, t. I, v. 1º , 231-292.

(1997c), «Ciudadanos de Zaragoza y comercio exterior del reino de Aragón», Studium. Revista de Humanidades, 3, 425-438.

(1997d), «Zaragoza, centro de abastecimiento de mercaderes castellanos a finales del siglo XIV», Aragón en la Edad Media, XIII, 125-158.

(1997e), «Las transformaciones fiscales en la génesis del Estado Moderno en Aragón», en M. González Jiménez (ed.), La Península Ibérica en la Era de los Descubrimientos (1391-1492), III Jornadas Hispano-Portuguesas de Historia Medieval, vol. 1, 551-560.

(1997f), en colaboración con J.A. García de Cortázar y Ruiz de Aguirre, Historia de la Edad Media. Una síntesis interpretativa, Madrid, Alianza.

(1998a), «El discreto magisterio de don José María Lacarra», Revista de Historia Jerónimo Zurita, 73, 69-87.

(1998b), «Aragón y Cataluña», en Historia de España Menéndez Pidal, t. IX La Reconquista y el proceso de diferenciación política (1035-1217), Madrid, EspasaCalpe, 661-752.

(1999a), «La nobleza bajomedieval y la formación del Estado moderno en la Corona de Aragón», en La nobleza peninsular en la Edad Media, VI Congreso de Estudios Medievales, Ávila, Fundación «Sánchez Albornoz», 345-430.

(1999b), «La fractura en la sociedad política catalana en vísperas del Compromiso de Caspe», Anuario de Estudios Medievales, 29, 1043-1066.

(1999c), «El ducado/principado de Gerona y la monarquía aragonesa bajomedieval», Aragón en la Edad Media, XIV-XV, vol. 2, 1507-1518. 
(1999d), «La reina doña Blanca y Aragón», Príncipe de Viana, 60, 35-48.

(1999e), en colaboración con C. Laliena Corbera, «La población de Barbastro y sus estrategias políticas y económicas a mediados del siglo XV», Revista d'historia medieval, 10, 123-160.

(1999f), en colaboración con G. Navarro Espinach, «Herbajes de ganaddos valencianos en tierras de Teruel (siglo xv)», Boletín de la Sociedad Castellonense de Cultura, 75, 783-801.

(2000a), La Corona de Aragón: una introducción crítica, Zaragoza, Caja de Ahorros de la Inmaculada.

(2000b), «El mercado de trabajo en Huesca y su área de influencia económica», Aragón en la Edad Media, 16, 739-756.

(2000c), «La sociedad aragonesa y sus relaciones con la conmunidad hebrea en vísperas de la expulsión», en F. Miranda (coord.), Movimientos migratorios y expulsiones en la diáspora occidental, Pamplona, Universidad Pública de Navarra-Gobierno de Navarra, 131-141.

(2000d), en colaboración con J.F. Utrilla Utrilla, Antología de textos sobre la economía aragonesa medieval, Zaragoza, Mira.

(2001a), «Del Cantábrico al Mediterráneo: la vía fluvial del Ebro», Itinerarios medievales e identidad hispánica, XXVII Semana de Estudios Medievales de Estella, Pamplona, Gobierno de Navarra, 189-220.

(2001b), «Fiscalidad de estado y comercio exterior en Aragón», Acta historica et archaeologica mediaevalia, 22, 459-467.

(2001c), «El bosque y su explotación económica para el mercado en el sur de Aragón en la Baja Edad Media», en J. Clemente Ramos (coord.), El medio natural en la España medieval, Cáceres, Universidad de Extremadura, 195-215.

(2001d), en colaboración con C. Laliena Corbera y J.F. Utrilla Utrilla, Agua y paisaje social en el Aragón medieval. Los regadíos del río Aguasvivas en la Edad Media, Zaragoza, Ministerio de Medio-Ambiente-Confederación Hidrográfica del Ebro, 2001.

(2002a), «Guerra, ejército y sociedad en los reinos de Aragón y Navarra en la Edad Media», Revista de Historia militar, 2, 13-48.

(2002b), «El poblamiento del espacio periurbano de Zaragoza a comienzos del siglo XIV», Poder y sociedad en la baja Edad Media. Estudios en Homenaje al profesor Luis Vicente Díaz Martín, Valladolid, Universidad de Valladolid, 1129-1141.

(2003a), «La creación de la memoria histórica, una selección interesada del pasado», Memoria, mito y realidad en la historia medieval, XIII Semana de Estudios Medievales de Nájera, Logroño, Instituto de Estudios Riojanos, 13-32.

(2003b), «La población urbana en la Corona de Aragón (siglos XIV-XV)», Las sociedades urbanas en la España medieval, XXIX Semana de Estudios Medievales de Estella, Pamplona, Gobierno de Navarra, 151-193.

(2003c), «Las ciudades de Aragón y Cataluña interior: población y flujos económicos (1150-1350)», en La città del Mediterraneo all'Apogeo dello sviluppo Medievale: 
Aspetti economici e sociali, XVIII Convegno internazionale di studi, Pistoia, Centro Italiano di Studi di Storia e d'Arte, 413-445.

(2004a), en colaboración con C. Laliena Corbera (coords.), La población de Aragón en la Edad Media (siglos XIII-XV) Estudios de demografía histórica, Zaragoza, Grupo CEMA-Universidad de Zaragoza.

(2005a) (ed.), Huesca, ciudad mercado de ámbito internacional en la Baja Edad Media según los registros de su aduana, Zaragoza, Departamento de Historia Medieval, Ciencias y Técnicas Historiográficas y Estudios Árabes e Islámicos.

(2005b), «Centros de producción y redes de distribución en los espacios interiores de la Corona de Aragón: materias primas y productos básicos», La Mediterrània de la Corona d'Aragó, segles XIII-XVI \& VII Centenari de la Sentència Arbitral de Torrellas, 1304-2004, XVIII Congrés d'Història de la Corona d'Aragó, Valencia, Generalitat, 903-938.

(2005c), «La Corona de Aragón y la monarquía hispánica», en De Hispania a España. El nombre y el concepto a través de los siglos, V. Palacio Atard (ed.), Madrid, Temas de Hoy, 121-136.

(2005d), «Reflexiones en torno a la guerra en la historia de la plena Edad Media (guerra, ejército y sociedad en Aragón. Siglos XI-XIII)», Cuadernos del CEMyR, 13, 229-248.

(2005e), «La concepción política de la Corona de Aragón: unidad y diversidad», en Fundamentos medievales de los particularismos hispánicos, IX Congreso de Estudios Medievales, Ávila, Fundación «Sánchez Albornoz», 205-220.

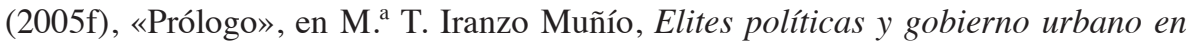
Huesca en la Edad Media, Huesca, Ayuntamiento, 13-15.

(2005g), en colaboración con C. Laliena Corbera, J.F. Utrilla Utrilla y M. ${ }^{\text {a T. Iranzo }}$ Muñío, Aragón, puerta de Europa. Los aragoneses y el Camino de Santiago en la Edad Media, Zaragoza, Gobierno de Aragón.

(2006a), Los Idus de diciembre de Fernando II. El atentado del rey de Aragón en Barcelona, Zaragoza, Grupo CEMA-Universidad de Zaragoza.

(2006b) (ed.), Cortes del reinado de Pedro IV/3, en Acta Curiarum regni Aragonum, t. IV, Zaragoza, Grupo CEMA, Gobierno de Aragón, Cortes de Aragón e Iber Caja. (2006c) (ed.), La vía del Somport en el comercio medieval de Aragón (Los registros de las aduanas de Jaca y Canfranc de mediados del siglo XV), Zaragoza, Departamento de Historia Medieval, Ciencias y Técnicas Historiográficas y Estudios Árabes e Islámicos.

(2006d), «El comercio en la Edad Media. Reflexiones para abrir una semana de estudios», El comercio en la Edad Media, XVI Semana de Estudios Medievales (Nájera y Tricio), Logroño, Instituto de Estudios Riojanos, 15-38.

(2006e), «¿Nueva monarquía de los Reyes Católicos?», Aragón en la Edad Media, XIX, 521-534. Otra edición en L.A. Ribot García, J. Valdeón Baruque y E. Maza Zorrilla (coords.), Isabel la Católica y su época, Valladolid, Instituto Universitario de Historia Simancas, 2007, 685-694. 
(2006f), «El mundo urbano en la Corona de Aragón (siglo XIII)», en M. González Jiménez (coord.), El mundo urbano en la Castilla del siglo XIII, Sevilla, Sociedad Española de Estudios Medievales, vol. 1, 203-218.

(2006g), en colaboración con C. Laliena Corbera y G. Navarro Espinach, «Prosopografía de las sociedades urbanas de Aragón durante los siglos XIV y XV: un balance provisional», en La prosopografía como método de investigación sobre la Edad Media, Zaragoza, Universidad de Zaragoza, 7-20.

(2006h), en colaboración con M. ${ }^{a}$ I. Falcón Pérez, «La escuela de medievalismo de Zaragoza», Medievalismo, 16, 257-267.

(2007a) (ed.), En el centenario de José María Lacarra (1907-2007): obra dispersa: trabajos publicados entre 1927 y 1944, Pamplona, Gobierno de Navarra, 5 vols.

(2007b), «Mercado inmobiliario en Zaragoza (1370-1420). La reorganización urbana bajomedieval», Mercado inmobiliario y paisajes urbanos en el Occidente Europeo (ss. XI-XV), XXXIV Semana de Estudios Medievales de Estella, Pamplona, Gobierno de Navarra, 2007, 417-470.

(2007c), «Le città aragonesi-catalane», en Tra economia e politica. Le corporazioni nell'Europa medievale, Pistoia, Centro Italiano di Studi di Storia e d'Arte, 163-186.

(2008a), «En el centenario de José María Lacarra. Semblanza», en Movimientos migratorios, asentamientos y expansión (siglos VIII-XI), XXXIV Semana de Estudios Medievales de Estella, Pamplona, Gobierno de Navarra, 23-31.

(2008b), en colaboración con M. Sánchez Martínez y A. Furió Diego, «Old and New Forms of Taxation in the Crown of Aragon (13th-14th Centuries)», La fiscalità nell'economia europea (sec. XIII-XVIII), XXXIX Settimana di Studi dell'Istituto Internazional di Storia Economica «Francesco Datini» di Prato, coord. S. Cavachiocci, Prato, 99-130.

(2008c), en colaboración con C. Laliena Corbera (coords.), La pervivencia del concepto. Nuevas reflexiones sobre la ordenación social del espacio en la Edad Media, Zaragoza, Grupo CEMA-Universidad de Zaragoza.

(2008d), en colaboración con J.A. García de Cortázar y Ruiz de Aguirre, Manual de Historia Medieval, Madrid, Alianza.

(2009a), (ed.), Cortes de los reinados de Pedro IV/4 y Juan I, en Acta Curiarum Regni Aragonum, t. V, Zaragoza, Grupo CEMA, Gobierno de Aragón, Cortes de Aragón e Iber Caja.

(2009b), en colaboración con C. Laliena Corbera (coords.), Crecimiento económico y formación de los mercados en Aragón en la Edad Media (1200-1350), Zaragoza, Grupo CEMA-Universidad de Zaragoza.

(2010a) (coord.), La Corona de Aragón en el centro de su Historia. 1208-1458. La monarquía aragonesa y los reinos de la Corona, Zaragoza, Grupo CEMA-Universidad de Zaragoza.

(2010b) (coord.), La Corona de Aragón en el centro de su Historia. 1208-1458. Aspectos económicos y sociales, Zaragoza, Grupo CEMA-Universidad de Zaragoza. 
(2010c) (ed.), El tráfico mercantil por las aduanas de Ribagorza (1444-1450), Zaragoza, Departamento de Historia Medieval, Ciencias y Técnicas Historiográficas y Estudios Árabes e Islámicos.

(2011a), El Interregno (1410-1412). Concordia y compromiso político en la Corona de Aragón, Zaragoza, Institución «Fernando el Católico».

(2011b) (coord.), La Corona de Aragón en el centro de su Historia. 1208-1458. El Interregno y el Compromiso de Caspe, Zaragoza, Grupo CEMA-Universidad de Zaragoza.

(2011c) (ed.), Parlamentos del Interregno, Acta Curiarum regni Aragonum, t. VII, Grupo CEMA, Gobierno de Aragón, Cortes de Aragón e Ibercaja, Zaragoza.

(2011d), «L'attività mercantile nelle fiere urbane del Basso Medioevo: Huesca (Aragona) a metà del XV secolo», en D, Balestracci (coord.), Uomini paesaggi storie: studi di storia medievale per Giovanni Cherubini, Siena, Università, vol. 1, 271-288.

(2011e), «Pedro IV y la proyección de la imagen real en la corona de Aragón», en P. Martínez Sopena y A. Rodríguez (eds.), La construcción medieval de la memoria regia, Valencia, Publicacions de la Universitat de Valencia, 415-424.

(2011f), «Consumo de productos alimenticios de lujo en la baja Edad Media», en Comer, beber, vivir. Consumo y niveles de vida en la Edad Media hispánica, XXI Semana de Estudios Medievales de Nájera, Logroño, Instituto de Estudios riojanos, 97-122.

(2012a), «El matrimonio de Fernando e Isabel y la unión de las Coronas de Castilla y Aragón», en En los umbrales de España. La invcorporación del reino de Navarra a la monarquía hispana, XXXVIII Semana de Estudios Medievales de Estella, Pamplona, Gobierno de Navarra, 27-56.

(2012b), «1412. El Compromiso de Caspe», en La Edad Media Hispánica: en torno a cuatro centenarios, Madrid, Real Academia de la Historia, 71-90.

(2012c), «El regne d'Aragó abans de l'expansió de Jaume I: ciutats i ciutadans», en R. Narbona Vizcaíno (coord.), Jaume I i el seu temps 800 anys després, Valencia, Publicaciones de la Universidad de Valencia, 195-206.

(2012d), «Actividad comercial y ferias mercantiles en Huesca (siglos XIII-XV)», en en C. Laliena Corbera y M. Lafuente Gómez, Una economía integrada. Comercio, instituciones y mercados en Aragón. 1300-1500, Zaragoza, Grupo CEMA-Universidad de Zaragoza, 265-290.

(2012e), «Presentación», en J. Abella Samitier, Sos en la Baja Edad Media. Una villa aragonesa de frontera, Zaragoza, Institución «Fernando el Católico», 5-10.

(2012f), en colaboración con C. Laliena Corbera y C. Monterde Albiac (eds.), En el Sexto Centenario de la Concordia de Alcañiz y del Compromiso de Caspe, Zaragoza, Gobierno de Aragón.

(2012g), «Puertos y navegación fluviales. El río Ebro en la Baja Edad Media», en Adela Fábregas García (ed.), Navegación y puertos en época medieval y moderna, Universidad de Granada, Granada, 44-67. 
(2013a), Fernando II y la Inquisición: el establecimiento de los tribunales inquisitoriales en la Corona de Aragón, 1479-1490, Madrid, Real Academia de la Historia. (2013b), Revolución comercial y cambio social: Aragón y el mundo mediterráneo, siglos XIV-XV, estudios reunidos por J.A. García de Cortázar y C. Laliena, Zaragoza, Prensas de la Universidad de Zaragoza.

(2013c), «Una vida de estudio», en J.A. Sesma Muñoz, Revolución comercial y cambio social: Aragón y el mundo mediterráneo, siglos XIV-XV, estudios reunidos por J.A. García de Cortázar y C. Laliena, Zaragoza, Prensas de la Universidad de Zaragoza, 31-40.

(2013d), en colaboración con M. Lafuente Gómez (eds.), Cortes de Pedro IV/1, Acta Curiarum regni Aragonum, t. II, Zaragoza, Grupo CEMA, Gobierno de Aragón, Cortes de Aragón e Ibercaja.

(2013e), en colaboración con J. Abella Samitier (eds.), Las aduanas de las Cinco Villas a mediados del siglo XV, Zaragoza, Departamento de Historia Medieval, Ciencias y Técnicas Historiográficas y Estudios Árabes e Islámicos.

(2014a), «La monarquía aragonesa», en E. Sarasa Sánchez (coord.), Monarquía, crónicas, archivos y cancillerías en los reinos hispano-cristianos, Zaragoza, Institución «Fernando el Católico», 69-76.

(2014b), «El rey, las Cortes y la gran nobleza. Aragón, 1347-1357», Miscelánea de estudios en homenaje a Guillermo Fatás Cabeza, Zaragoza, Institución «Fernando el Católico», 657-665.

(2014c), «Prólogo», en M. Lafuente Gómez, Un reino en armas. La guerra de los Dos Pedros en Aragón (1356-1366), Zaragoza, Institución «Fernando el Católico», 7-10.

(2014d), en colaboración con C. Laliena Corbera (coords.), De la escritura a la historia (Aragón, siglos XIII-XV), Zaragoza, Grupo CEMA-Universidad de Zaragoza.

(2015a), «La burbuja censualista y las crisis financieras en Aragón. Ajustes y medidas de rescate para evitar la bancarrota (siglos XIV-XV)», en Estados y mercados financieros en el Occidente cristiano (siglos XIII-XVI), XLI Semana de Estudios Medievales de Estella, Pamplona, Gobierno de Navarra, 215-241.

(2015b), en colaboración con C. Morte García y J.F. Méndez de Juan (dirs.), Fernando II. El rey que imaginó España y la abrió a Europa, Catálogo de la exposición, Palacio de la Ajafería (Zaragoza), 10 de marzo-7 de junio de 2015, Zaragoza, Gobierno de Aragón.

(2015c), «Fernando II y el reino de Aragón. Aportación a un centenario», Dara. Documentos y Archivos de Aragón. Novedades, 15 (junio 2015), 4-6.

(2015d), en colaboración con C. Laliena, M. ${ }^{a}$ C. García Herrero, G. Navarro, M. ${ }^{a}$ T. Iranzo, C. Villanueva y M. Lafuente, en C. Villanueva Morte y M. Lafuente Gómez (coords.), Documentos del concejo de Zaragoza. Edición crítica de los fondos del Archivo Municipal. I: 1285-1348, Departamento de Historia Medieval, Ciencias y Técnicas Historiográficas y Estudios Árabes e Islámicos, Zaragoza, Universidad de Zaragoza. 
(2015e), en colaboración con C. Laliena Corbera, «Acta Curiarum Regni Aragonum. La publicación de las actas de las Cortes medievales de Aragón», Dara. Documentos y Archivos de Aragón. Novedades, 14 (marzo 2015), 18-20.

\section{Otras obras}

ARÓSTEGUI SÁNCHEZ, J. (2004), La Historia vivida. Sobre la Historia del presente, Madrid, Alianza.

AZNAR VALLEJO, E. (2014), «La Universidad de La Laguna», en M.A. Ladero Quesada, Poder político y sociedad en Castilla. Siglos XIII al XV, estudios reunidos por José Manuel Nieto Soria, Madrid, Dykinson, 13-18.

BELTRÁN SUÁREZ, S. y M. ÁLVAREZ FERNÁNDEZ, (2015), «Perfil de un medievalista», en S. Beltrán Suárez y M. Álvarez Fernández, J.I. Ruiz de la Peña Solar. Estudios de Historia Medieval, Oviedo, Universidad de Oviedo, vol. 1, 9-11.

BORRERO FERNÁNDEZ, M. (2011), «Un maestro de investigadores en los «orígenes» de Andalucía», en M. González Jiménez, Cuatro décadas de estudios medievales, Sevilla, Universidad de Sevilla, 15-26.

- (2014), «La Universidad de Sevilla», en M.A. Ladero Quesada, Poder político y sociedad en Castilla. Siglos XIII al XV, estudios reunidos por José Manuel Nieto Soria, Madrid, Dykinson, 19-24.

BRAUDEL, F. (2002), Las ambiciones de la Historia, Barcelona, Crítica.

CANTERA MONTENEGRO, E., M. CANTERA MONTENEGRO y S. CANTERA MONTENEGRO (2014), «La Universidad Complutense de Madrid», en M.A. Ladero Quesada, Poder político y sociedad en Castilla. Siglos XIII al XV, estudios reunidos por José Manuel Nieto Soria, Madrid, Dykinson, 29-34.

CARRASCO PÉREZ, Juan (2012), «Tres decenios de Historia de la fiscalidad: reflexiones de un historiador», en A. Galán Sánchez y E. García Fernández, En busca de Zaqueo: los recaudadores de impuestos en las épocas medieval y moderna, Madrid, Instituto de Estudios Fiscales, 15-24.

CÓRDOBA DE LA LLAVE, R., J.L. DEL PINO GARCÍA y M. CABRERA SÁNCHEZ (2015), «Prólogo», en Estudios en homenaje al profesor Emilio Cabrera, Córdoba, Universidad de Córdoba-Universidad de Extremadura, 11-16.

DYER, Ch. (1989), Niveles de vida en la Baja Edad Media, Barcelona, Crítica.

FREEDMAN, P. y J.M. ${ }^{a}$ MUÑOZ I LLORET (2003), «Un historiador que sabía dónde quería ir. La obra de Jaume Vicens Vives en su contexto biográfico», en P. Freedman y J.M. ${ }^{a}$ Muñoz i Lloret (eds.), Jaume Vicens Vives, Juan II de Aragón (1398-1479): monarquía y revolución en la España del siglo XV, Pamplona, Urgoiti, XI-CIV.

GARCÍA DE CORTÁZAR Y RUIZ DE AGUIRRE, J.A. (2009a), «Atomización o el regionalismo. La Historia despedazada o invertebrada», en La Historia Medieval hoy. Percepción académica y percepción social, XXXV Semana de Estudios Medievales de Estella, Pamplona, Gobierno de Navarra, 343-380. 
GARCÍA DE CORTÁZAR Y RUIZ DE AGUIRRE, J.A. (2009b), «La historiografía de tema medieval hispano: una reflexión sobre el oficio y la producción del medievalista en los años 1982 a 2007», en E. De Vega (ed.), 25 años de historia: la revista Studia Historica en la historiografía española, Salamanca, Universidad de Salamanca, 63-86.

(2011), «Manuel González Jiménez en la distancia: coordenadas de una vida de investigación como medievalista», en M. González Jiménez, Cuatro décadas de estudios medievales, Sevilla, Universidad de Sevilla, 27-50.

- (2013), «Introducción», en J.A. Sesma Muñoz, Revolución comercial y cambio social: Aragón y el mundo mediterráneo, siglos XIV-XV, estudios reunidos por J.A. García de Cortázar y C. Laliena, Zaragoza, Prensas de la Universidad de Zaragoza, 9-16.

IGGERS, G.G. (2012), La historiografía del siglo xx. Desde la objetividad científica al desafio posmoderno, Santiago de Chile, Fondo de cultura Económica.

IRADIEL MURUGARREN, P. (1999), «Ciudades, comercio y economía artesana», en La historia medieval en España. Un balance historiográfico (1968-1998), XXV Semana de Estudios Medievales de Estella, Pamplona, Gobierno de Navarra, 603-658.

JOVER ZAMORA, J.M. (1997), «Auge y decadencia de España. Trayectoria de una mitología histórica en el pensamiento español», en Historia y civilización. Escritos seleccionados, Valencia, Publicacions de la Universitat de Valéncia, 63-92.

JULIÁ, S. (2009), Historia social/Sociología histórica, Madrid, Siglo XXI (prólogo de Pablo Sánchez León).

LADERO QUESADA, M.A. (2013), «Contestación», en J.A. Sesma Muñoz, Fernando II y la Inquisición: el establecimiento de los tribunales inquisitoriales en la Corona de Aragón, 1479-1490, Madrid, Real Academia de la Historia, 2013.

(2014), Poder político y sociedad en Castilla. Siglos XIII al XV, estudios reunidos por José Manuel Nieto Soria, Madrid, Dykinson.

- (2015), «Lo antiguo y lo nuevo de la investigación sobre fiscalidad y poder político en la Baja Edad Media hispánica», en Estados y mercados financieros en el Occidente cristiano (siglos XIII-XVI), XLI Semana de Estudios Medievales de Estella, Pamplona, Gobierno de Navarra, 13-54.

LALIENA CORBERA, C. (2012), «Transformación social y revolución comercial en Aragón: treinta años de investigación», en C. Laliena Corbera y M. Lafuente Gómez, Una economía integrada. Comercio, instituciones y mercados en Aragón. 1300-1500, Zaragoza, Grupo CEMA-Universidad de Zaragoza, 13-68.

- (2013), «José Ángel Sesma, un perfil historiográfico», en J.A. Sesma Muñoz, Revolución comercial y cambio social: Aragón y el mundo mediterráneo, siglos XIVXV, estudios reunidos por J.A. García de Cortázar y C. Laliena, Zaragoza, Prensas de la Universidad de Zaragoza. 
MARÍN GELABERT, M.A. (2005), Los historiadores españoles en el franquismo, 1948-1975, Zaragoza, Institución «Fernando el Católico».

— (2007), «La formación de un medievalista: José María Lacarra, 1907-1940», Revista de Historia Jerónimo Zurita, 82, 39-98.

MARTÍN DUQUE, A. (1999), «Las «Semanas de Estella» y el medievalismo hispánico. Un ensayo de «egohistoria»», La historia medieval en España. Un balance historiográfico (1968-1998), XXV Semana de Estudios Medievales de Estella, Pamplona, Gobierno de Navarra, 23-49.

NIETO SORIA, J.M., «La historia política: retos inmediatos» (2003), en F. Sabaté y J. Farré (eds.), Lérida, Medievalisme: noves perspectives, VII Curs d'Estiu Comtat d'Urgell, 43-61.

(2014), «Presentación», en M.A. Ladero Quesada, Poder político y sociedad en Castilla. Siglos XIII al XV, estudios reunidos por José Manuel Nieto Soria, Madrid, Dykinson, 5-9.

PASAMAR ALZURÍA, G. (2004), «Las «Historias de España» a lo largo del siglo xx: las transformaciones de un género clásico», en R. García Cárcel (coord.), La construcción de las Historias de España, Madrid, Marcial Pons, 299-381.

PEÑA BOCOS, E. (2012), «El Profesor García de Cortázar y su Magisterio en la Universidad de Cantabria: El Metropolitano toma el Metropolitano para ir al Metropolitano», en Mundos medievales. Espacios, sociedades y poder, Homenaje al profesor José Ángel García de Cortázar y Ruiz de Aguirre, Santander, Ediciones de la Universidad de Cantabria, v. 1, 11-32.

RAPHAEL, L. (2012), La ciencia histórica en la era de los extremos. Teorías, métodos y tendencias desde 1900 hasta la actualidad, Zaragoza, Institución «Fernando el Católico».

RIVIÈRE GÓMEZ, A. (2000), «Envejecimiento del presente y dramatización del pasado: una aproximación a las síntesis históricas de las Comunidades Autónomas españolas (1975-1995)», en J.S. Pérez Garzón (coord.), La gestión de la memoria. La Historia de España al servicio del poder, Barcelona, Crítica, 161-219.

RUIZ DE LA PEÑA SOLAR, J.I. (2009), «Cuatro acreedores preferentes del medievalismo español: Eduardo Hinojosa, Ramón Menéndez Pidal, Manuel GómezMoreno y Claudio Sánchez Albornoz», en La Historia Medieval hoy. Percepción académica y percepción social, XXXV Semana de Estudios Medievales de Estella, Pamplona, Gobierno de Navarra, 193-230.

SÁNCHEZ MARTÍNEZ, M. (2006), «José Luis Martín, investigador de la Historia de Cataluña», Anuario de Estudios Medievales, 36/1, 491-505.

SÁNCHEZ SAUS, R. (2014), «La Universidad de Cádiz», en M.A. Ladero Quesada, Poder político y sociedad en Castilla. Siglos XIII al XV, estudios reunidos por José Manuel Nieto Soria, Madrid, Dykinson, 25-28.

SOLÓRZANO TELECHEA, J.A. (2012), «Presentación», en Mundos medievales. Espacios, sociedades y poder, Homenaje al profesor José Ángel García de Cortá- 
zar y Ruiz de Aguirre, Santander, Ediciones de la Universidad de Cantabria, v. 1, XXI-XXV.

SEIBT, F. y W. EBERHARD (eds.) (1993), Europa 1400. La crisis de la baja Edad Media, Barcelona, Crítica.

VAL VALDIVIESO, M.I. Del (2009), «Semblanza de Julio Valdeón», en M.I. Del Val Valdivieso y P. Martínez Sopena, Castilla y el mundo feudal. Homenaje al profesor Julio Valdeón, Valladolid, Junta de Castilla-León y Universidad de Valladolid, 7-11. 